Article

\title{
Salt Stress Amelioration in Maize Plants through Phosphogypsum Application and Bacterial Inoculation
}

\author{
Tamer Khalifa $^{1}$ (D), Mohssen Elbagory ${ }^{2,3}$ and Alaa El-Dein Omara ${ }^{3, * \mathbb{D}}$ \\ 1 Agricultural Research Center, Department of Soil Improvement and Conservation, Soils, Water and \\ Environment Research Institute, Giza 12112, Egypt; tamerkhalifa1985@gmail.com \\ 2 Department of Biology, Faculty of Science and Arts, King Khalid University, Mohail Assir 61321, Saudi Arabia; \\ mhmohammad@kku.edu.sa \\ 3 Agricultural Research Center, Department of Microbiology, Soils, Water and Environment Research Institute, \\ Giza 12112, Egypt \\ * Correspondence: alaa.omara@yahoo.com
}

Citation: Khalifa, T.; Elbagory, M.; Omara, A.E.-D. Salt Stress

Amelioration in Maize Plants through Phosphogypsum Application and Bacterial Inoculation. Plants 2021, 10, 2024. https://doi.org/10.3390/ plants10102024

Academic Editors: Ewa Hanus-Fajerska and Iwona Kamińska

Received: 1 August 2021

Accepted: 22 September 2021

Published: 27 September 2021

Publisher's Note: MDPI stays neutral with regard to jurisdictional claims in published maps and institutional affiliations.

Copyright: (c) 2021 by the authors. Licensee MDPI, Basel, Switzerland. This article is an open access article distributed under the terms and conditions of the Creative Commons Attribution (CC BY) license (https:/ / creativecommons.org/licenses/by/ $4.0 /)$.

\begin{abstract}
The use of phosphogypsum (PG) and plant growth-promoting rhizobacteria (PGPR) for agricultural purposes are good options to improve soil properties and increase crop yield. The objective of this study was to investigate the effect of different rates of PG (ton ha ${ }^{-1} ; 0$ (PG1), 3 (PG2), 6 (PG3), and 9 (PG4)) combined with PGPR inoculation (Azospirillum lipoferum (control, T1), A. lipoferum + Bacillus coagulans (T2), A. lipoferum + B. circulance (T3), and A. lipoferum + B. subtilis (T4)) on soil properties, plant physiology, antioxidant enzymes, nutrient uptake, and yield of maize plants (Zea mays L., cv. HSC 10) grown in salt-affected soil. Over two growing seasons, 2019 and 2020, field experiments were conducted as a split-plot design with triplicates. The results show that applying PG ( 9 ton ha ${ }^{-1}$ ) and co-inoculation (A. lipoferum + B. circulance) treatment significantly increased chlorophyll and carotenoids content, antioxidant enzymes, microbial communities, soil enzymes activity, and nutrient contents, and showed inhibitory impacts on proline content and $\mathrm{pH}$, as well as EC and ESP, thus improving the productivity of maize plant compared to the control treatment. It could be concluded that PG, along with microbial inoculation, may be an important approach for ameliorating the negative impacts of salinity on maize plants.
\end{abstract}

Keywords: phosphogypsum; PGPR; soil salinity; nutrient content; maize productivity

\section{Introduction}

In arid and semi-arid regions, soil salinity has been reported to have a negative impact on soil quality and crop growth, affecting 25 to $30 \%$ of the crop productivity of agricultural soils [1-3]. In addition, salinity is a major environmental stress and a major obstacle to crop production. The salinization of arable land is expected to have devastating effects globally, resulting in $30 \%$ of lost land over the next 25 years and up to $50 \%$ by the mid-21st century [4]. Nowadays, $50 \%$ of the world's total cultivated area is exposed to salinity stress, causing a loss of about USD 12 billion [5]. In addition, soil salinity is a complex process that has negative effects on the activity of physiological and biochemical processes in the plant [6]. Therefore, the toxicity of specific ions during metabolic processes or osmotic stress leads to a reduction in plant growth, nutrient uptake, and enzyme activity [7,8]. On the other hand, the adverse effects of salt-affected soils are associated with the reduced osmosis (primary stage) and cytotoxicity of ions (secondary stage), as well as the production of reactive oxygen species (ROS) and nutrient imbalance [9]; high osmotic stress is related to the accumulation of soluble salts in the soil solution, which leads to water stress [10]. According to [11], the inhibitory effect of salinity stress on the growth and productivity of different crops depends on several factors, such as salt concentration in the soil solution, time interval, plant species, plant growth stage, gas exchange properties, photosynthetic pigments, and environmental conditions. Therefore, it is important to explore 
sustainable management practices to reduce the harmful effect of this problem through genetic techniques, breeding programs of crops for salinity tolerance, soil conditioners, and biological products [12-14]. Within these practices, beneficial microorganisms (plant growth-promoting rhizobacteria, PGPR) play an important role in ameliorating salt stress and the ability to release nutrients from organic and inorganic forms to soluble forms, which appears to be a promising process for enhancing the tolerance of crops to salinity [15]. Several researchers have suggested that PGPR may be applicable in enhancing crop production under salt stress by enhancing the nutrient uptake physiological modifications, and antioxidant activities of plants [16-18]. Several PGPR genera, including Pseudomonas, Bacillus, Azospirillum, Bradyrhizobium, and Flavobacterium are known to improve the growth and productivity of different crops grown in salinity-affected soils. PGPR can be attached to the roots of plants, such as endophytes, rhizoplane, or rhizosphere $[19,20]$.

Rock-bearing nutrients, along with plant growth-promoting bacteria, are a recent alternative strategy to synthetic chemical fertilizers. In this context, phosphogypsum (PG) is a by-product of the phosphate fertilizer industry, resulting from the production of phosphoric acid from rock phosphate (fluorapatite). Worldwide, about 160 million tons of phosphogypsum are produced annually and it is primarily disposed of in large stocks or discharged into water bodies [21]. It contains mostly sulfur, calcium oxide, and small amounts of phosphorous [22] and heavy metals, as well as impurities of radioactive elements [23]. As the hazardous effects of PG waste in the environment are increasing due to continued industrialization, proper management is required to minimize the adverse effects on humans and the ecosystem [24]. In different countries around the world, phosphogypsum is used in agriculture either as a soil amendment (calcium sulfate) or as fertilizer [25], which may be an efficient amendment to reclaim alkaline soils by improving the soil properties and the availability of different nutrients to crops (direct) or in combination with microbes to enhance the solubility of nutrients (indirect) [26]. Several investigators have suggested that synergistic application with PG and microbial inoculation increased the levels of NPK uptake and enhanced the growth of maize plants [26], enhancing the microbial biomass carbon, $\mathrm{N}$ concentrations, soil enzyme, and plant growth $[27,28]$. Therefore, the objective of this study was to investigate the application effects of different rates of PG combined with microbial inoculation on chemical and biological soil properties, plant physiology, antioxidant enzymes, the contents of macro- and micronutrients, and the yield of maize plants grown in salt-affected soil.

\section{Results}

\subsection{Physiological Characteristics in Maize Leaves}

In both seasons (2019 and 2020), the contents of the chlorophyll ( $\left.\mathrm{mg} \mathrm{g}^{-1} \mathrm{FW}\right)$, carotenoids $\left(\mu \mathrm{g} \mathrm{g}^{-1} \mathrm{FW}\right)$, and proline $\left(\mu \mathrm{mole} \mathrm{g}^{-1} \mathrm{FW}\right)$ of maize leaves at 60 days after sowing showed significant differences $(p<0.05)$ with respect to different applications of phosphogypsum (PG1 (0 t ha $\left.{ }^{-1}\right)$, PG2 (3 tha $\left.{ }^{-1}\right)$, PG3 $\left(6 \mathrm{t} \mathrm{ha}^{-1}\right)$, and PG4 $\left.\left(9 \mathrm{t} \mathrm{ha}^{-1}\right)\right)$ and microbial inoculations (A. lipoferum (control, T1), A. lipoferum + B. coagulans (T2), A. lipoferum + B. circulance (T3), and A. lipoferum + B. subtilis (T4)) (Table 1). Generally, highly significant differences were observed for the chlorophyll and carotenoids parameters with increasing PG rates and microbial inoculations, and thus, the results occurred in the descending order of PG4 > PG3 > PG2 > PG1 for different phosphogypsum rates and T3 > T2 > T4 > T1 for different microbial inoculations. On the contrary, the proline content parameter showed decreasing values with increasing rates of PG during the two growing seasons (Table 1). In addition, the combined application treatment (PG4 + T3) was the best treatment among all tested applications. For instance, in the 2019 season, the highest values of $2.73 \mathrm{mg} \mathrm{g}^{-1} \mathrm{FW}$ and $0.970 \mu \mathrm{g} \mathrm{g}^{-1} \mathrm{FW}$ were recorded for chlorophyll and carotenoid contents, respectively, while the PG3 + T3 treatment showed the lowest value $\left(6.16 \mu \mathrm{mole}^{-1} \mathrm{FW}\right)$ for proline content compared to the other treatments and the control (Table 1). A similar trend was observed in the 2020 season. 
Table 1. The combined effect of different rates of phosphogypsum and microbial inoculations on total chlorophyll, carotenoids and proline contents in maize leaves grown in salt-affected soils during the 2019 and 2020 seasons.

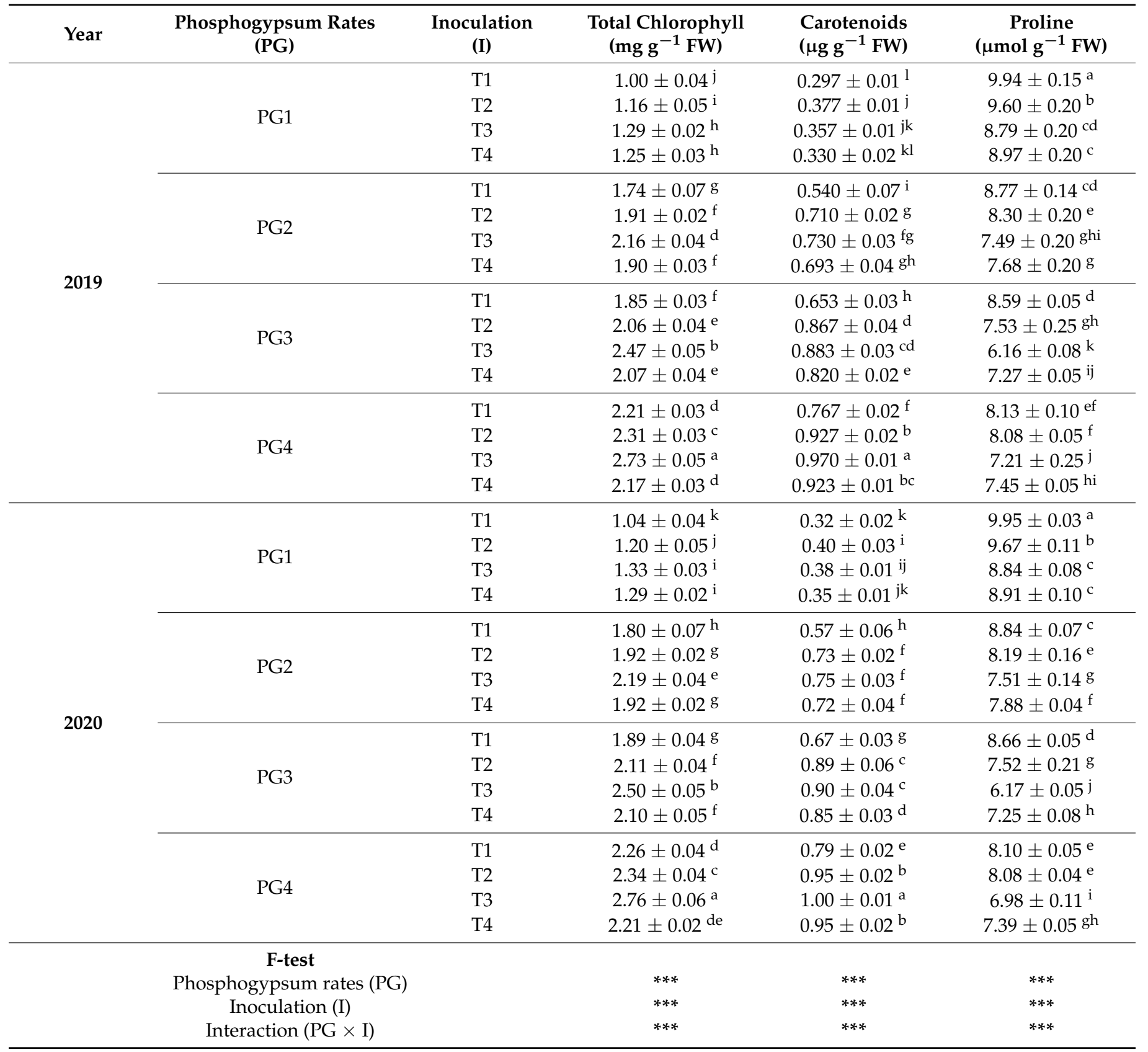

Means of the same growing season designated with different letters indicate significant differences among treatments according to the Duncan test $(p<0.05)$. Values are the means \pm standard deviation (SD) from 3 replicates (mean $\pm \mathrm{SD}$ ). PG1 $-0 \mathrm{t} \mathrm{ha}^{-1}$; PG2-3 tha ${ }^{-1}$; PG3-6 $\mathrm{t} \mathrm{ha}^{-1}$; PG4-9 $\mathrm{t} \mathrm{ha}^{-1}$; T1-A. lipoferum (control); T2-A. lipoferum + B. coagulans; T3-A. lipoferum + B. circulance, and T4-A. lipoferum + B. subtilis; ***-High significant.

\subsection{Antioxidant Enzyme Activities}

The data presented in Figure 1 show that activities of catalase (CAT), ascorbate peroxidase (APX), and peroxidase (POX) were significantly changed due to the PG rates and microbial inoculation treatments at 60 days after sowing. The highest rate of PG added to the maize plants grown in salt-affected soil increased the activity of the CAT enzyme compared to the lowest addition rate. Interestingly, CAT activity is directly proportional to the increased rates of PG used in this study. Treated maize plants with PG4 (9 ton ha ${ }^{-1}$ ) significantly increased CAT activity $\left(\mu \mathrm{M} \mathrm{H}_{2} \mathrm{O}_{2} \mathrm{~g}^{-1} \mathrm{FW} \mathrm{min}^{-1}\right)$ from 20.07 (A. lipoferum, T1) to 23.27 (A. lipoferum + B. coagulans, T2), 24.82 (A. lipoferum + B. circulance, T3), and 
28.18 (A. lipoferum + B. subtilis, T4) in the 2019 season, whereas in the 2020 season, the same rate of PG increased CAT activity from 20.25 (A. lipoferum, T1) to 23.66 (A. lipoferum $+B$. coagulans, T2), 25.07 (A. lipoferum + B. circulance, T3), and 28.32 (A. lipoferum + B. subtilis, T4) significantly, as shown in Figure 1A. From the results mentioned above, PG4 application and inoculation with A. lipoferum + B. circulance (T3) was the best treatment compared to other application treatments. In the same way, the application of PG and microbial inoculation alleviated the detrimental effect of salinity on the antioxidant capacity represented in APX activity. APX activity ( $\mu \mathrm{M} \mathrm{H}_{2} \mathrm{O}_{2} \mathrm{~g}^{-1} \mathrm{FW} \mathrm{min}^{-1}$ ) changed significantly from 383.67 (A. lipoferum, $\mathrm{T} 1)$ to 428.67 (A. lipoferum + B. coagulans, T2), 434.00 (A. lipoferum + B. circulance, T3), and 456.00 (A. lipoferum + B. subtilis, T4) in the 2019 season. Likewise, in the 2020 season, the recorded APX activity was 391.67 (A. lipoferum, T1), 434.67 (A. lipoferum + B. coagulans, T2), 441.00 (A. lipoferum + B. circulance, T3), and 460.00 (A. lipoferum + B. subtilis, T4) when PG was applied with a rate of 9 ton $\mathrm{ha}^{-1}$. Among all treatments, the PG4 rate and T3 treatment had the highest values of APX activity (Figure 1B). A similar trend was observed for the POX activity, for which the PG4 rate with the T3 treatment was the best among all tested applications recorded, with 2.37 unit $\min ^{-1} \mathrm{~g}^{-1} \mathrm{FW}$ and 2.43 unit $\mathrm{min}^{-1} \mathrm{~g}^{-1} \mathrm{FW}$, respectively (Figure $1 \mathrm{C}$ ).
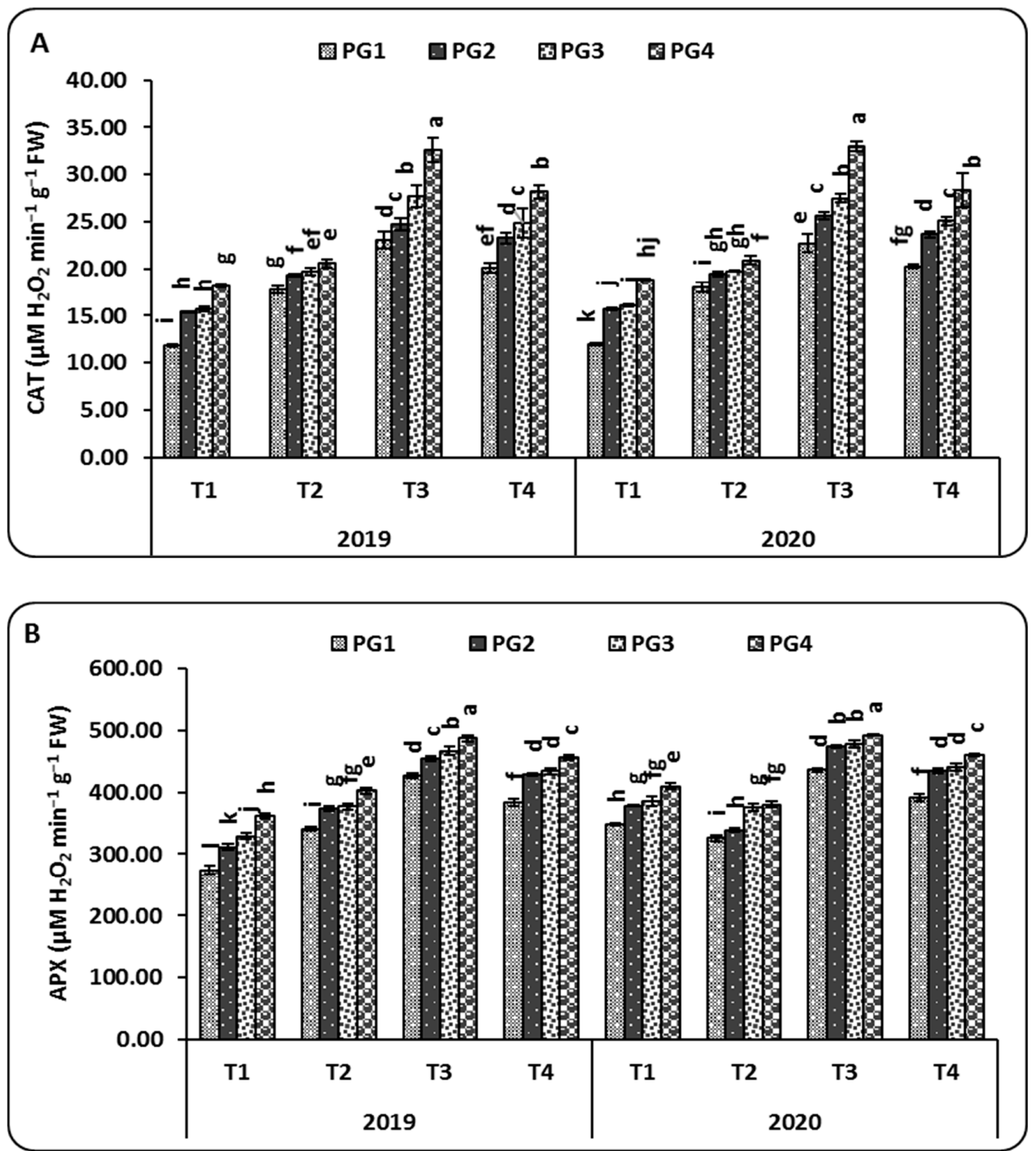

Figure 1. Cont. 


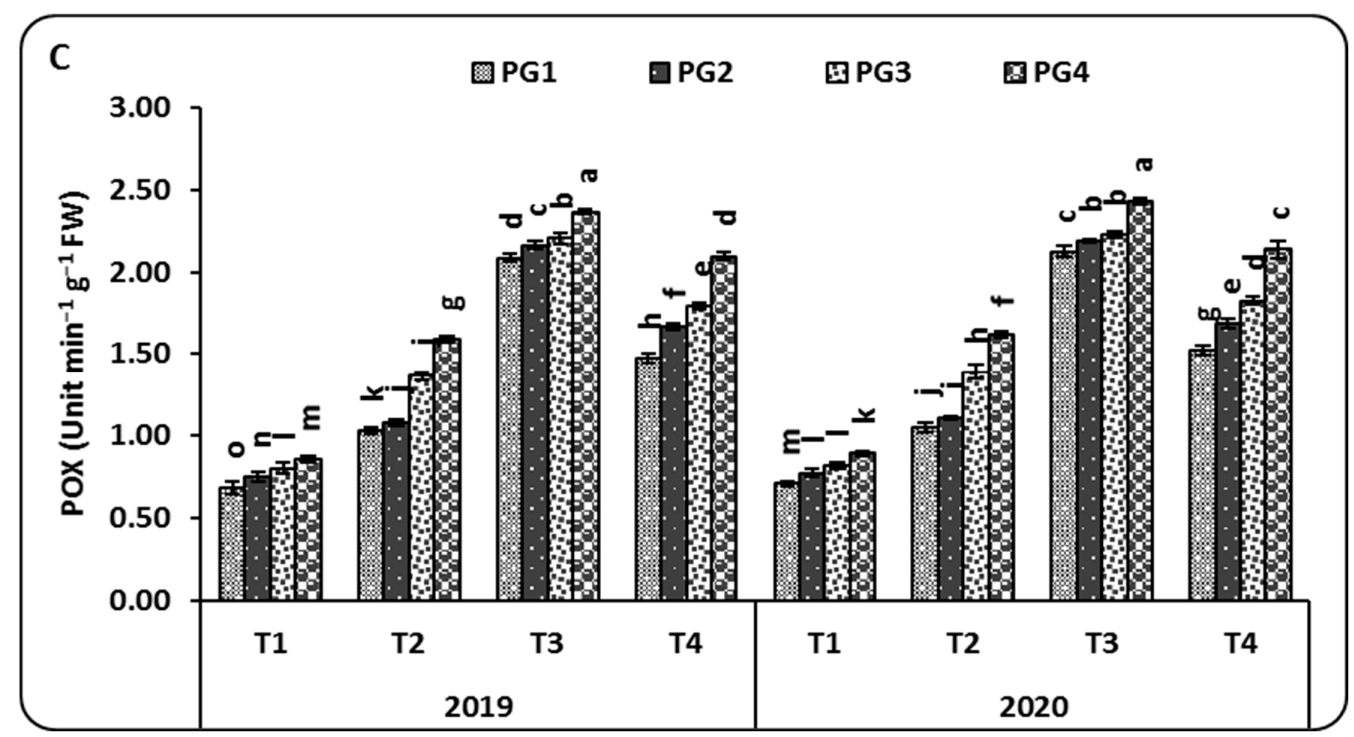

Figure 1. The combined effect of different rates of phosphogypsum and microbial inoculations on catalase (CAT) (A), ascorbate peroxidase (APX) (B), and peroxidase (POX) (C) activities in maize leaves grown in salt-affected soils during the 2019 and 2020 seasons. Means of the same growing season designated with different letters indicate significant differences among treatments according to the Duncan test $(p<0.05)$. Values are the means \pm standard deviation (SD) from 3 replicates (means $\pm \mathrm{SD}$ ). PG1-0 $\mathrm{t} \mathrm{ha}^{-1}$; PG2-3 $\mathrm{tha}^{-1}$; PG3-6 $\mathrm{tha}^{-1}$; PG4-9 $\mathrm{t} \mathrm{ha}^{-1}$; $\mathrm{T} 1-$ A. lipoferum (control); $\mathrm{T} 2-$ A. lipoferum + B. coagulans; T3-A. lipoferum + B. circulance, and T4-A. lipoferum + B. subtilis.

\subsection{Microbial Communities}

After two months from the time of sowing, the microbial communities, that is, the total count of Azospirillum, the total count of Bacillus, and the total count of bacteria in the rhizosphere of maize plants grown in salt-affected soil, were significant with respect to soil salinity and the application of PG and the microbial inoculation treatments $(p<0.05)$ in both the 2019 and 2020 seasons (Figure 2).

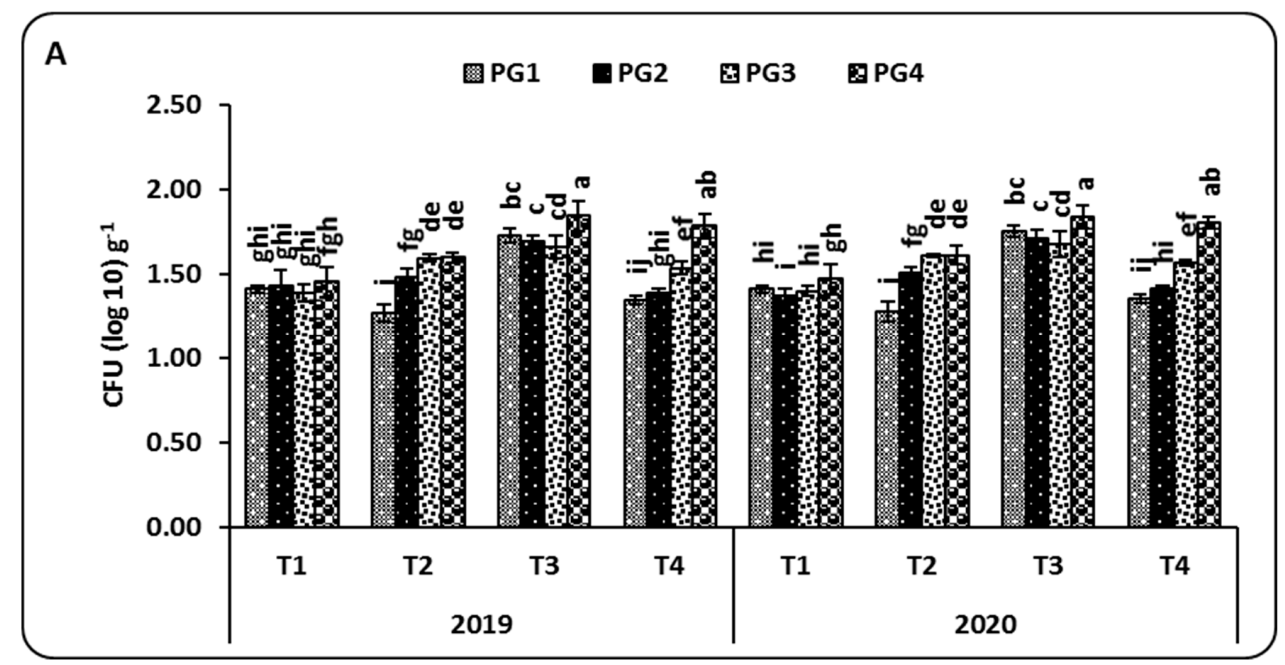

Figure 2. Cont. 

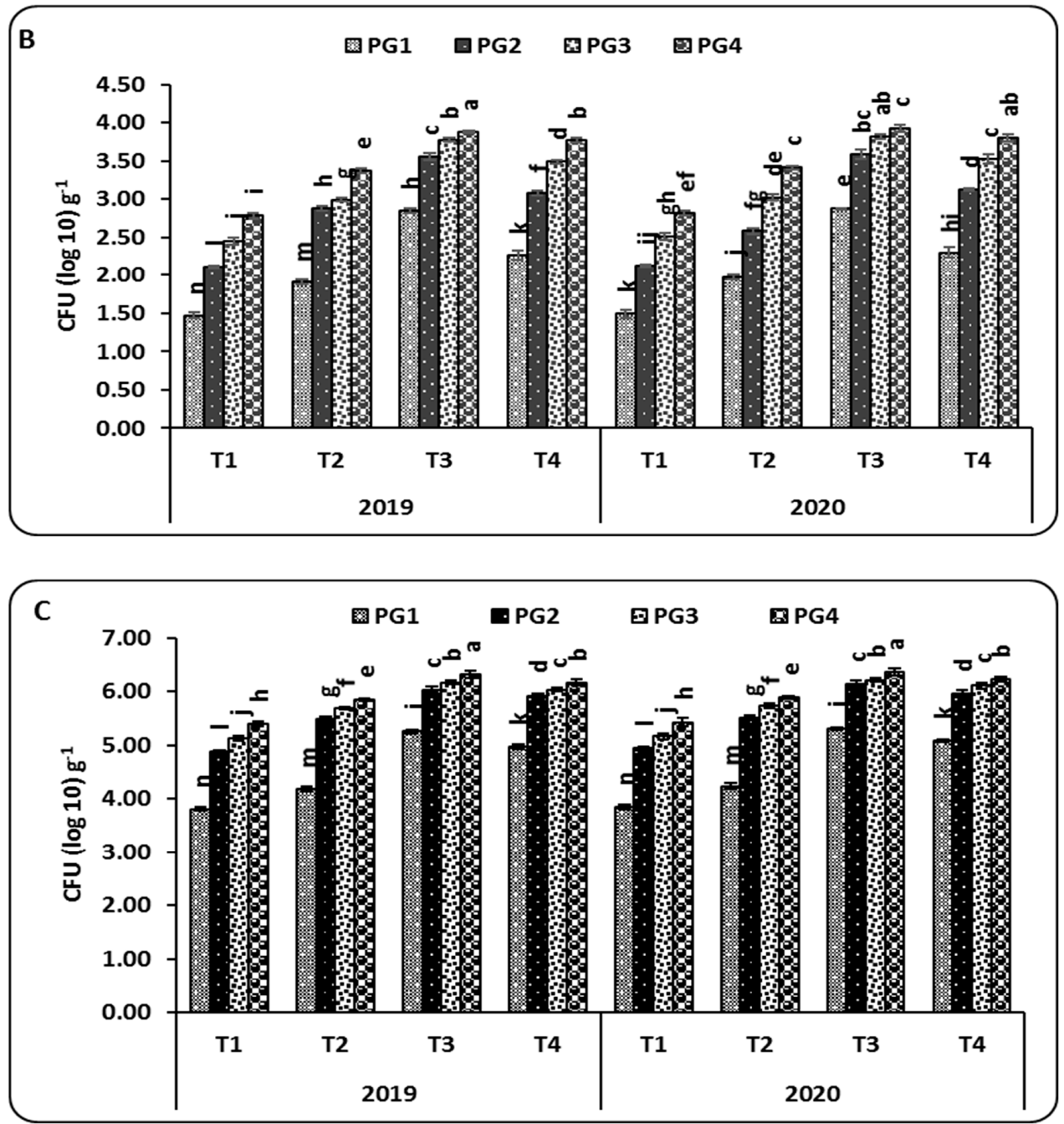

Figure 2. The combined effect of different rates of phosphogypsum and microbial inoculations on the total count of Azospirillum (A), the total count of Bacillus (B), and the total count of bacteria (C) in the rhizosphere of maize plants grown in salt-affected soils during the 2019 and 2020 seasons. Means of the same growing season designated with different letters indicate significant differences among treatments according to the Duncan test $(p<0.05)$. Values are the means \pm standard deviation (SD) from 3 replicates (means $\pm \mathrm{SD}$ ). PG1-0 $\mathrm{tha}^{-1}$; PG2-3 $\mathrm{tha}^{-1}$; PG3-6 tha ${ }^{-1}$; PG4-9 $\mathrm{t} \mathrm{ha}^{-1}$; T1-A. lipoferum (control); T2-A. lipoferum + B. coagulans; T3-A. lipoferum + B. circulance, and T4-A. lipoferum + B. subtilis.

In general, the results illustrate that different rates of PG attained differences in the microbial communities, showing a descending order of PG4 (9 ton ha $\left.{ }^{-1}\right)>$ PG3 $\left(6\right.$ ton ha $\left.{ }^{-1}\right)>$ PG2 $\left(3 \mathrm{t} \mathrm{ha}^{-1}\right)>$ PG1 $\left(0 \mathrm{t} \mathrm{ha}^{-1}\right)$. On the other hand, the T3 treatment (A. lipoferum + B. circulance) showed the highest populations compared to the other treatments, with total counts of 1.85 and 1.84 CFU $\log 10 \mathrm{~g}^{-1}$ of Azospirillum (Figure 2A), 3.88 and 3.92 CFU $\log 10 \mathrm{~g}^{-1}$ of Bacillus (Figure 2B), and 6.32 and $6.37 \mathrm{CFU} \log 10 \mathrm{~g}^{-1}$ of bacteria (Figure 2C) during the 2019 and 2020 seasons, respectively.

\subsection{Soil Enzyme Activities}

Dual inoculation with Azospirillum and different strains of Bacillus showed increases in the soil enzyme activity (dehydrogenase (DHA) and urease) in the rhizosphere of maize plants significantly with the single inoculation (Azospirillum only, control) under different application rates of phosphogypsum at 60 days after sowing (Table 2). Generally, dehydrogenase and urease activity was noted to increase with increasing phosphogyp- 
sum rates. The highest DHA activity, compared to other treatments, was 216.00 and $222.00 \mathrm{mg} \mathrm{TPF} \mathrm{g}^{-1}$ soil day $^{-1}$, followed by 190.00 and $195.00 \mathrm{mg} \mathrm{TPF} \mathrm{g}^{-1}$ soil day $^{-1}$ for the PG4T3 treatment ( 9 ton ha ${ }^{-1}$ and A. lipoferum + B. circulance) and the PG4T4 treatment ( 9 ton ha ${ }^{-1}$ and A. lipoferum + B. subtilis) during the 2019 and 2020 seasons, respectively (Table 2). On the other hand, under different application rates of PG, the T3 treatment (A. lipoferum + B. circulance) was the best inoculation treatment for urease enzyme activity, with recorded rates of $89.00,97.00,124.33$, and $138.00 \mathrm{NH}_{4}{ }^{+}-\mathrm{N} \mathrm{g}^{-1}$ soil day ${ }^{-1}$ in the 2019 season and 91.00, 99.00, 130.00, and $143.00 \mathrm{NH}_{4}{ }^{+}-\mathrm{N} \mathrm{g}^{-1}$ soil day ${ }^{-1}$ in the 2020 season for $0,3,6$, and $9 \mathrm{t} \mathrm{ha}^{-1}$ of PG, respectively. From the results mentioned above, PG4 and A. lipoferum + B. circulance treatment was the best treatment compared to other tested treatments (Table 2).

Table 2. The combined effect of different rates of phosphogypsum and microbial inoculations on soil enzyme activity (dehydrogenase and urease) in the rhizosphere of maize plants grown in salt-affected soils during the 2019 and 2020 seasons.

\begin{tabular}{|c|c|c|c|c|}
\hline Year & $\begin{array}{l}\text { Phosphogypsum Rates } \\
\text { (PG) }\end{array}$ & $\begin{array}{l}\text { Inoculation } \\
\text { (I) }\end{array}$ & $\begin{array}{c}\text { DHA } \\
\left(\mathrm{mg} \mathrm{TPF}^{-1} \text { Soil } \mathrm{d}^{-1}\right)\end{array}$ & $\begin{array}{c}\text { Urease } \\
\left(\mathrm{NH}_{4}{ }^{+}-1 \mathrm{~N} \mathrm{~g}^{-1} \text { Soil Day }\right. \\
\end{array}$ \\
\hline \multirow{16}{*}{2019} & \multirow{4}{*}{ PG1 } & $\mathrm{T} 1$ & $50.00 \pm 4.58^{1}$ & $45.33 \pm 1.53^{\mathrm{j}}$ \\
\hline & & $\mathrm{T} 2$ & $74.00 \pm 2.65^{\mathrm{k}}$ & $58.33 \pm 3.51^{\mathrm{i}}$ \\
\hline & & $\mathrm{T} 3$ & $80.00 \pm 3.00 \mathrm{jk}$ & $89.00 \pm 3.61^{\mathrm{e}}$ \\
\hline & & $\mathrm{T} 4$ & $84.00 \pm 4.00^{\mathrm{j}}$ & $71.33 \pm 3.79 \mathrm{~h}$ \\
\hline & \multirow{4}{*}{ PG2 } & $\mathrm{T} 1$ & $104.67 \pm 5.51^{\mathrm{i}}$ & $57.00 \pm 2.65^{i}$ \\
\hline & & $\mathrm{T} 2$ & $147.33 \pm 5.69^{\mathrm{f}}$ & $71.00 \pm 2.00^{h}$ \\
\hline & & $\mathrm{T} 3$ & $184.33 \pm 4.16^{\mathrm{c}}$ & $97.00 \pm 2.00^{\mathrm{d}}$ \\
\hline & & $\mathrm{T} 4$ & $169.33 \pm 5.51^{\mathrm{d}}$ & $82.67 \pm 3.21^{f}$ \\
\hline & \multirow{4}{*}{ PG3 } & $\mathrm{T} 1$ & $122.33 \pm 5.51^{h}$ & $68.67 \pm 2.52^{h}$ \\
\hline & & $\mathrm{T} 2$ & $158.33 \pm 4.04^{\mathrm{e}}$ & $77.67 \pm 3.51^{\mathrm{g}}$ \\
\hline & & $\mathrm{T} 3$ & $201.33 \pm 3.51^{b}$ & $124.33 \pm 3.51^{b}$ \\
\hline & & $\mathrm{T} 4$ & $176.00 \pm 3.61^{\mathrm{d}}$ & $92.67 \pm 3.51^{\mathrm{e}}$ \\
\hline & \multirow{4}{*}{ PG4 } & $\mathrm{T} 1$ & $134.33 \pm 4.16^{\mathrm{g}}$ & $76.33 \pm 2.08 \mathrm{~g}$ \\
\hline & & $\mathrm{T} 2$ & $172.00 \pm 4.58^{\mathrm{d}}$ & $89.67 \pm 3.06^{\mathrm{e}}$ \\
\hline & & $\mathrm{T} 3$ & $216.00 \pm 5.57^{\mathrm{a}}$ & $138.00 \pm 4.58^{\mathrm{a}}$ \\
\hline & & $\mathrm{T} 4$ & $190.00 \pm 3.61^{c}$ & $106.00 \pm 4.36^{\mathrm{c}}$ \\
\hline \multirow{16}{*}{2020} & \multirow{4}{*}{ PG1 } & $\mathrm{T} 1$ & $51.67 \pm 3.51^{n}$ & $46.67 \pm 2.08^{1}$ \\
\hline & & $\mathrm{T} 2$ & $77.67 \pm 0.58^{\mathrm{m}}$ & $61.33 \pm 1.53 \mathrm{k}$ \\
\hline & & $\mathrm{T} 3$ & $81.67 \pm 3.21^{\mathrm{m}}$ & $91.00 \pm 3.46^{\mathrm{f}}$ \\
\hline & & $\mathrm{T} 4$ & $87.00 \pm 2.65^{1}$ & $76.00 \pm 3.61^{\mathrm{i}}$ \\
\hline & \multirow{4}{*}{ PG2 } & $\mathrm{T} 1$ & $111.00 \pm 2.65^{k}$ & $60.33 \pm 4.73^{k}$ \\
\hline & & $\mathrm{T} 2$ & $151.33 \pm 3.51^{h}$ & $72.33 \pm 3.21^{\mathrm{j}}$ \\
\hline & & $\mathrm{T} 3$ & $187.00 \pm 3.61^{\mathrm{d}}$ & $99.67 \pm 2.08^{d}$ \\
\hline & & $\mathrm{T} 4$ & $172.33 \pm 5.69^{f}$ & $82.67 \pm 1.15 \mathrm{~g}$ \\
\hline & \multirow{4}{*}{ PG3 } & $\mathrm{T} 1$ & $129.67 \pm 1.53^{j}$ & $70.33 \pm 3.51 \mathrm{j}$ \\
\hline & & $\mathrm{T} 2$ & $162.00 \pm 3.61 \mathrm{~g}$ & $80.00 \pm 4.58 \mathrm{gh}$ \\
\hline & & $\mathrm{T} 3$ & $209.67 \pm 1.15^{b}$ & $130.00 \pm 3.61^{b}$ \\
\hline & & $\mathrm{T} 4$ & $179.00 \pm 4.00^{\mathrm{e}}$ & $95.00 \pm 4.00^{\mathrm{e}}$ \\
\hline & \multirow{4}{*}{ PG4 } & $\mathrm{T} 1$ & $138.33 \pm 4.04^{\mathrm{i}}$ & $78.67 \pm 1.53 \mathrm{hi}$ \\
\hline & & $\mathrm{T} 2$ & $175.33 \pm 3.79$ ef & $91.67 \pm 3.51$ ef \\
\hline & & $\mathrm{T} 3$ & $222.67 \pm 5.51^{a}$ & $143.33 \pm 4.51^{\mathrm{a}}$ \\
\hline & & $\mathrm{T} 4$ & $195.00 \pm 6.08^{c}$ & $112.67 \pm 5.69^{c}$ \\
\hline \multirow{3}{*}{ F-test } & \multicolumn{2}{|c|}{ Phosphogypsum rates (PG) } & $* * *$ & $* * *$ \\
\hline & \multicolumn{2}{|c|}{ Inoculation (I) } & $* * *$ & $* * *$ \\
\hline & \multicolumn{2}{|c|}{ Interaction $(\mathrm{PG} \times \mathrm{I})$} & $* * *$ & $* * *$ \\
\hline
\end{tabular}

Means of the same growing season designated with different letters indicate significant differences among treatments according to the Duncan test $(p<0.05)$. Values are the means \pm standard deviation (SD) from 3 replicates (means \pm SD). PG1-0 tha ${ }^{-1}$; PG2-3 $\mathrm{t} \mathrm{ha}^{-1} ; \mathrm{PG} 3-6 \mathrm{tha}^{-1} ; \mathrm{PG} 4-9 \mathrm{tha}^{-1} ; \mathrm{T} 1-$ A. lipoferum (control); T2-A. lipoferum + B. coagulans; T3-A. lipoferum + B. circulance, and T4-A. lipoferum + B. subtilis; ${ }^{* * *}$-High significant. 


\subsection{Macro-Elements, $\mathrm{Na}^{+}$and $\mathrm{K}^{+} / \mathrm{Na}^{+} \%$ in Maize Leaves}

Under different rates of $\mathrm{PG}$, the inoculation of Azospirillum and their mixture with different strains of Bacillus (B. coagulans, B. circulance, and B. subtilis) led to increases in the percentages of the macroelements $\mathrm{N}, \mathrm{P}$, and $\mathrm{K}^{+}$and the $\mathrm{K}^{+} / \mathrm{Na}^{+}$ratio as well as decreases in the percentage of $\mathrm{Na}$ in maize leaves, with significant differences at 60 days after sowing (Table 3).

Table 3. The combined effect of different rates of phosphogypsum and microbial inoculations on the percentages of N, P, K, and $\mathrm{Na}$ and the K/Na ratio in maize leaves grown in salt-affected soils during the 2019 and 2020 seasons.

\begin{tabular}{|c|c|c|c|c|c|c|c|}
\hline Year & $\begin{array}{l}\text { Phosphogypsum } \\
\text { Rates (PG) }\end{array}$ & $\begin{array}{l}\text { Inoculation } \\
\text { (I) }\end{array}$ & $\mathbf{N}$ & $\mathbf{P}$ & $\mathbf{K}$ & $\mathrm{Na}$ & $\mathrm{K} / \mathrm{Na}$ \\
\hline \multirow{16}{*}{2019} & \multirow{4}{*}{ PG1 } & $\mathrm{T} 1$ & $1.03 \pm 0.03^{1}$ & $0.24 \pm 0.02^{1}$ & $0.98 \pm 0.03^{k}$ & $2.18 \pm 0.04^{a}$ & $0.44 \pm 0.02 \mathrm{~m}$ \\
\hline & & $\mathrm{T} 2$ & $1.07 \pm 0.04^{1}$ & $0.26 \pm 0.02^{k}$ & $1.00 \pm 0.02^{k}$ & $2.08 \pm 0.04^{b}$ & $0.48 \pm 0.02^{\mathrm{lm}}$ \\
\hline & & $\mathrm{T} 3$ & $1.34 \pm 0.02^{h}$ & $0.37 \pm 0.02^{\mathrm{i}}$ & $1.33 \pm 0.03^{e f}$ & $1.43 \pm 0.02^{j}$ & $0.93 \pm 0.01^{\mathrm{e}}$ \\
\hline & & $\mathrm{T} 4$ & $1.14 \pm 0.03^{\mathrm{k}}$ & $0.34 \pm 0.02^{j}$ & $1.25 \pm 0.01 \mathrm{~g}$ & $1.71 \pm 0.03 \mathrm{fg}$ & $0.73 \pm 0.02 \mathrm{~g}$ \\
\hline & \multirow{4}{*}{ PG2 } & $\mathrm{T} 1$ & $1.18 \pm 0.03^{j}$ & $0.34 \pm 0.02^{j}$ & $1.05 \pm 0.04^{j}$ & $1.95 \pm 0.02^{c}$ & $0.53 \pm 0.02^{\mathrm{kl}}$ \\
\hline & & $\mathrm{T} 2$ & $1.25 \pm 0.03^{\mathrm{i}}$ & $0.48 \pm 0.04 \mathrm{~g}$ & $1.16 \pm 0.03 \mathrm{hi}$ & $1.88 \pm 0.03^{\mathrm{d}}$ & $0.61 \pm 0.022^{\mathrm{ij}}$ \\
\hline & & $\mathrm{T} 3$ & $1.71 \pm 0.03^{\mathrm{e}}$ & $0.65 \pm 0.02^{c}$ & $1.60 \pm 0.04^{c}$ & $1.20 \pm 0.02^{\mathrm{k}}$ & $1.33 \pm 0.04^{c}$ \\
\hline & & $\mathrm{T} 4$ & $1.41 \pm 0.03^{g}$ & $0.52 \pm 0.03^{f}$ & $1.36 \pm 0.03^{\mathrm{e}}$ & $1.59 \pm 0.04^{h}$ & $0.85 \pm 0.03^{f}$ \\
\hline & \multirow{4}{*}{ PG3 } & $\mathrm{T} 1$ & $1.33 \pm 0.03^{h}$ & $0.43 \pm 0.02^{h}$ & $1.07 \pm 0.02^{j}$ & $1.83 \pm 0.03^{\mathrm{e}}$ & $0.58 \pm 0.01^{j \mathrm{k}}$ \\
\hline & & $\mathrm{T} 2$ & $1.35 \pm 0.02^{h}$ & $0.54 \pm 0.02^{\mathrm{f}}$ & $1.19 \pm 0.02^{h}$ & $1.68 \pm 0.05^{g}$ & $0.70 \pm 0.01 \mathrm{gh}$ \\
\hline & & $\mathrm{T} 3$ & $1.76 \pm 0.03^{\mathrm{d}}$ & $0.68 \pm 0.02^{b}$ & $1.87 \pm 0.02^{b}$ & $1.05 \pm 0.04^{1}$ & $1.78 \pm 0.09^{b}$ \\
\hline & & $\mathrm{T} 4$ & $1.54 \pm 0.03^{\mathrm{f}}$ & $0.58 \pm 0.01^{\mathrm{e}}$ & $1.36 \pm 0.03^{\mathrm{e}}$ & $1.49 \pm 0.02^{\mathrm{i}}$ & $0.91 \pm 0.01^{\text {ef }}$ \\
\hline & \multirow{4}{*}{ PG4 } & $\mathrm{T} 1$ & $1.67 \pm 0.03^{\mathrm{e}}$ & $0.49 \pm 0.02 \mathrm{~g}$ & $1.13 \pm 0.03^{i}$ & $1.73 \pm 0.04^{f}$ & $0.65 \pm 0.03 \mathrm{hi}$ \\
\hline & & $\mathrm{T} 2$ & $1.92 \pm 0.03^{c}$ & $0.62 \pm 0.02^{d}$ & $1.30 \pm 0.03^{f}$ & $1.75 \pm 0.02^{\mathrm{f}}$ & $0.74 \pm 0.02^{g}$ \\
\hline & & $\mathrm{T} 3$ & $2.11 \pm 0.04^{\mathrm{a}}$ & $0.76 \pm 0.03^{a}$ & $1.97 \pm 0.02^{\mathrm{a}}$ & $0.85 \pm 0.03^{\mathrm{m}}$ & $2.31 \pm 0.06^{\mathrm{a}}$ \\
\hline & & $\mathrm{T} 4$ & $2.04 \pm 0.05^{b}$ & $0.67 \pm 0.02 b c$ & $1.45 \pm 0.04^{\mathrm{d}}$ & $1.39 \pm 0.03^{j}$ & $1.04 \pm 0.04^{\mathrm{d}}$ \\
\hline \multirow{16}{*}{2020} & \multirow{4}{*}{ PG1 } & $\mathrm{T} 1$ & $1.05 \pm 0.02^{k}$ & $0.28 \pm 0.03^{1}$ & $1.01 \pm 0.03^{\mathrm{k}}$ & $2.16 \pm 0.02^{\mathrm{a}}$ & $0.45 \pm 0.01^{1}$ \\
\hline & & $\mathrm{T} 2$ & $1.07 \pm 0.02^{\mathrm{k}}$ & $0.30 \pm 0.02^{1}$ & $1.04 \pm 0.03^{1}$ & $2.01 \pm 0.07^{b}$ & $0.50 \pm 0.02^{\mathrm{kl}}$ \\
\hline & & $\mathrm{T} 3$ & $1.40 \pm 0.02^{h}$ & $0.40 \pm 0.02^{j}$ & $1.36 \pm 0.01^{1}$ & $1.39 \pm 0.02^{\mathrm{i}}$ & $0.97 \pm 0.00^{\mathrm{e}}$ \\
\hline & & $\mathrm{T} 4$ & $1.20 \pm 0.02^{\mathrm{j}}$ & $0.36 \pm 0.03^{\mathrm{k}}$ & $1.32 \pm 0.02^{\text {efg }}$ & $1.62 \pm 0.02 \mathrm{~g}$ & $0.81 \pm 0.03 \mathrm{~g}$ \\
\hline & \multirow{4}{*}{ PG2 } & $\mathrm{T} 1$ & $1.22 \pm 0.02^{j}$ & $0.39 \pm 0.01^{\mathrm{jk}}$ & $1.06 \pm 0.03^{g}$ & $1.91 \pm 0.03^{c}$ & $0.55 \pm 0.03^{k}$ \\
\hline & & $\mathrm{T} 2$ & $1.30 \pm 0.03^{\mathrm{i}}$ & $0.49 \pm 0.01^{h}$ & $1.19 \pm 0.05^{\mathrm{kl}}$ & $1.81 \pm 0.02^{\mathrm{d}}$ & $0.65 \pm 0.01^{\mathrm{ij}}$ \\
\hline & & $\mathrm{T} 3$ & $1.75 \pm 0.02^{\mathrm{d}}$ & $0.69 \pm 0.02^{c}$ & $1.64 \pm 0.03^{\mathrm{hi}}$ & $1.18 \pm 0.02^{\mathrm{k}}$ & $1.38 \pm 0.08^{c}$ \\
\hline & & $\mathrm{T} 4$ & $1.49 \pm 0.06^{\mathrm{g}}$ & $0.57 \pm 0.02^{f}$ & $1.40 \pm 0.08^{\mathrm{e}}$ & $1.53 \pm 0.02^{h}$ & $0.91 \pm 0.02^{f}$ \\
\hline & \multirow{4}{*}{ PG3 } & $\mathrm{T} 1$ & $1.31 \pm 0.05^{\mathrm{i}}$ & $0.46 \pm 0.02^{\mathrm{i}}$ & $1.10 \pm 0.01^{j k}$ & $1.79 \pm 0.03^{\mathrm{d}}$ & $0.61 \pm 0.01^{j}$ \\
\hline & & $\mathrm{T} 2$ & $1.39 \pm 0.01^{h}$ & $0.56 \pm 0.03^{f}$ & $1.23 \pm 0.04^{h}$ & $1.65 \pm 0.06^{\mathrm{fg}}$ & $0.74 \pm 0.02^{h}$ \\
\hline & & $\mathrm{T} 3$ & $1.81 \pm 0.03^{c}$ & $0.72 \pm 0.02^{b}$ & $1.91 \pm 0.03^{b}$ & $1.00 \pm 0.02^{1}$ & $1.91 \pm 0.04^{b}$ \\
\hline & & $\mathrm{T} 4$ & $1.63 \pm 0.02^{f}$ & $0.62 \pm 0.02^{\mathrm{e}}$ & $1.39 \pm 0.02^{\text {ef }}$ & $1.43 \pm 0.01^{\mathrm{i}}$ & $0.97 \pm 0.01^{\mathrm{e}}$ \\
\hline & \multirow{4}{*}{ PG4 } & $\mathrm{T} 1$ & $1.69 \pm 0.03^{\mathrm{e}}$ & $0.53 \pm 0.02^{g}$ & $1.16 \pm 0.02^{\mathrm{ij}}$ & $1.68 \pm 0.02 \mathrm{ef}$ & $0.69 \pm 0.00^{\mathrm{i}}$ \\
\hline & & $\mathrm{T} 2$ & $2.03 \pm 0.05^{b}$ & $0.66 \pm 0.01^{d}$ & $1.34 \pm 0.03^{\mathrm{fg}}$ & $1.70 \pm 0.02^{\mathrm{e}}$ & $0.78 \pm 0.01 \mathrm{gh}$ \\
\hline & & $\mathrm{T} 3$ & $2.19 \pm 0.03^{a}$ & $0.80 \pm 0.03^{a}$ & $1.99 \pm 0.02^{a}$ & $0.80 \pm 0.01 \mathrm{~m}$ & $2.48 \pm 0.02^{a}$ \\
\hline & & $\mathrm{T} 4$ & $2.15 \pm 0.04^{\mathrm{a}}$ & $0.69 \pm 0.03^{c}$ & $1.48 \pm 0.04^{\mathrm{d}}$ & $1.35 \pm 0.03^{j}$ & $1.09 \pm 0.02^{\mathrm{d}}$ \\
\hline \multirow{3}{*}{ F-test } & \multicolumn{2}{|c|}{ Phosphogypsum rates (PG) } & $* * *$ & $* * *$ & $* * *$ & $* * *$ & $* * *$ \\
\hline & \multicolumn{2}{|c|}{ Inoculation (I) } & $* * *$ & $* * *$ & $* * *$ & $* * *$ & $* * *$ \\
\hline & \multicolumn{2}{|c|}{ Interaction $(\mathrm{PG} \times \mathrm{I})$} & $* * *$ & $* * *$ & $* * *$ & $* * *$ & $* * *$ \\
\hline
\end{tabular}

Means of the same growing season designated with different letters indicate significant differences among treatments according to the Duncan test $(p<0.05)$. Values are the means \pm standard deviation (SD) from 3 replicates (means \pm SD). PG1-0 tha ${ }^{-1}$; PG2-3 tha ${ }^{-1}$; PG3-6 tha ${ }^{-1}$; PG4-9 tha ${ }^{-1} ; \mathrm{T} 1-$ A. lipoferum (control); T2-A. lipoferum + B. coagulans; T3-A. lipoferum + B. circulance, and T4-A. lipoferum + B. subtilis; ***_High significant.

Under 9 t ha $^{-1}$ of PG, the T3 treatment (seeds inoculated with Azospirillum + B. circulance) gave the highest percentages of $\mathrm{N}, \mathrm{P}$, and $\mathrm{K}$ compared to the control treatment (seeds inoculated with Azospirillum only), attaining increased rates of $26.3 \%$ and $29.5 \%$ for N, 
$55.1 \%$ and $50.9 \%$ for $\mathrm{P}$ and $74.3 \%$ and $71.5 \%$ for K during both the 2019 and 2020 seasons, respectively (Table 3).

On the other hand, the percentage of $\mathrm{Na}^{+}$decreased with the soil application of PG and microbial inoculation treatments. The greatest reduction in the percentage of $\mathrm{Na}^{+}$was in maize leaves grown with the application of PG4 $\left(9 \mathrm{tha}^{-1}\right)$, which decreased from $1.73 \%$ (A. lipoferum, T1) to $1.75 \%$ (A. lipoferum + B. coagulans, T2), $0.85 \%$ (A. lipoferum + B. circulance, T3), and $1.39 \%$ (A. lipoferum + B. subtilis, T4) in the 2019 season, whereas in the 2020 season, the same rate of $\mathrm{PG}$ decreased the percentage of $\mathrm{Na}^{+}$from $1.68 \%$ (A. lipoferum, $\mathrm{T} 1$ ) to $1.70 \%$ (A. lipoferum + B. coagulans, T2), $0.80 \%$ (A. lipoferum + B. circulance, T3), and $1.35 \%$ (A. lipoferum + B. subtilis, T4) significantly, as shown in (Table 3$)$. In the same way, the T3 treatment (A. lipoferum + B. circulance) showed an increase in the $\mathrm{K}^{+} / \mathrm{Na}^{+}$ratio, with recorded rates of $0.93 \%\left(0 \mathrm{tha}^{-1}\right), 1.33 \%\left(3 \mathrm{tha}^{-1}\right), 1.78 \%\left(6 \mathrm{tha}^{-1}\right)$, and $2.31 \%\left(9 \mathrm{t} \mathrm{ha}^{-1}\right)$ in the 2019 season; whereas in the 2020 season, the recorded rates were $0.97 \%\left(0 \mathrm{tha}^{-1}\right)$, $1.38 \%\left(3 \mathrm{t} \mathrm{ha}^{-1}\right), 1.91 \%\left(6 \mathrm{t} \mathrm{ha}^{-1}\right)$, and $2.48 \%\left(9 \mathrm{t} \mathrm{ha}^{-1}\right)$ compared to the other treatments under study (Table 3$)$.

\subsection{Micro-Elements in Maize Leaves}

Field trials were carried out using a moderately salt-sensitive genotype of maize plants (Zea mays L., cv. HSC 10) in the presence of $0,3,6$, and $9 \mathrm{t} \mathrm{ha}^{-1}$ of PG. The plants were exposed to different rates of $\mathrm{PG}$, and when bacterized with dual-inoculation (Azospirillum + Bacillus), they showed significantly higher levels of plant micro-elements than single-inoculated plants (Azospirillum only) (Table 4). After 60 days from sowing, the PG rate $\left(9 \mathrm{tha}^{-1}\right)$ led to increases of $47.9,20.08,16.24$, and $7.07 \%$ in maize leaves for $\mathrm{Zn}, \mathrm{Mn}$, $\mathrm{Fe}$, and $\mathrm{Cu}(\mathrm{ppm})$, respectively, under the $\mathrm{T} 3$ treatment (A. lipoferum + B. circulance) compared to the control treatment during the 2019 season. A similar trend was observed in the 2020 season (Table 4). Thus, the PG4 rate $\left(9\right.$ ton ha $\left.{ }^{-1}\right)$ showed the highest content of microelements (ppm) in maize plants than the other studied PG rates and the descending order of PG4 with microbial inoculation was as follows: PG4T3 (A. lipoferum + B. circulance) $>$ PG4T4 (A. lipoferum + B. subtilis) $>$ PG4T2 (A. lipoferum + B. coagulans) $>$ PG4T1 (control) (Table 4).

\subsection{Soil Physicochemical Characteristics}

At harvest (120 DAS), and by comparing the initial soil traits, the applications of different PG rates and microbial inoculation treatments changed the physicochemical characteristics properties of the soil (Figure 3). It was found that the $\mathrm{pH}$ decremented gradually with increasing PG rates (PG2, PG3, and PG4). The highest decrease in pH was observed with the combined application of PG4 $\left(9 \mathrm{t} \mathrm{ha}^{-1}\right)$ and T3 (A. lipoferum + B. circulance) in both the 2019 and 2020 seasons. The use of the combined or individual applications of PG and microbial inoculation significantly improved the soil EC compared to the control plants in both the 2019 and 2020 seasons (Figure 3). The soil EC ( $\mathrm{dS} \mathrm{m}^{-1}$ ) changed significantly from 6.22 (A. lipoferum, T1) to 6.02 (A. lipoferum + B. coagulans, T2), 5.07 (A. lipoferum + B. circulance, T3), and 5.49 (A. lipoferum + B. subtilis, T4) in the 2019 season. Likewise, in the 2020 season, the recorded rates of soil EC were 5.89 (A. lipoferum, T1), 5.76 (A. lipoferum + B. coagulans, T2), 4.60 (A. lipoferum + B. circulance, T3), and 5.05 (A. lipoferum + B. subtilis, T4) when PG was applied at a rate of $9 \mathrm{tha}^{-1}$ (Figure 3). On the other hand, the combined treatment (PG4 + T3) was the best treatment for ESP, as the highest values of 8.44 and $8.18 \%$ were recorded in the 2019 and 2020 seasons, respectively, as compared to the other treatments (Figure 3).

\subsection{Maize Productivity}

The results (Table 5) revealed that inoculation treatments in combination with PG showed significant influence on grains yield $\left(\mathrm{kg} \mathrm{ha}^{-1}\right)$ and yield-related parameters (ear length, ear diameter, grains/ear, and 100-grain weight), under salt-affected soil conditions during the two growing seasons. 
The combination treatment (A. lipoferum + B. circulance) with PG4 $\left(9\right.$ ton ha $\left.{ }^{-1}\right)$ caused the maximum values of ear length $(\mathrm{cm})$, ear diameter $(\mathrm{cm})$, and grains/ear, recorded as $24.20,4.70$ and 458.00 , respectively, compared to the single inoculation with the PG4 treatment (control), recorded as 18.23, 4.33, and 433.33 in the 2019 season, respectively. Likewise, in the 2020 season, the same trend was observed (Table 5).

Table 4. The combined effect of different rates of phosphogypsum and microbial inoculations on micro-nutrients (mg Kg ${ }^{-1}$ ) in maize leaves grown in salt-affected soils during the 2019 and 2020 seasons.

\begin{tabular}{|c|c|c|c|c|c|c|}
\hline Year & $\begin{array}{c}\text { Phosphogypsum } \\
\text { Rates (PG) }\end{array}$ & $\begin{array}{l}\text { Inoculation } \\
\text { (I) }\end{array}$ & $\mathrm{Zn}$ & Mn & $\mathrm{Fe}$ & $\mathrm{Cu}$ \\
\hline \multirow{16}{*}{2019} & \multirow{4}{*}{ PG1 } & $\mathrm{T} 1$ & $23.73 \pm 0.32^{\mathrm{m}}$ & $23.55 \pm 0.38^{n}$ & $55.04 \pm 0.22^{j}$ & $7.17 \pm 0.06^{h}$ \\
\hline & & $\mathrm{T} 2$ & $25.36 \pm 0.45^{1}$ & $24.43 \pm 0.27^{\mathrm{m}}$ & $61.75 \pm 0.11^{\mathrm{i}}$ & $7.44 \pm 0.04^{g}$ \\
\hline & & T3 & $35.67 \pm 0.32^{h}$ & $26.42 \pm 0.32^{k}$ & $75.31 \pm 0.19$ efg & $7.74 \pm 0.05^{\mathrm{e}}$ \\
\hline & & $\mathrm{T} 4$ & $28.82 \pm 0.20^{\mathrm{k}}$ & $25.19 \pm 0.17^{1}$ & $66.29 \pm 0.10^{\mathrm{h}}$ & $7.60 \pm 0.09^{f}$ \\
\hline & \multirow{4}{*}{ PG2 } & $\mathrm{T} 1$ & $29.84 \pm 0.44^{j}$ & $27.45 \pm 0.33^{j}$ & $67.69 \pm 0.17^{h}$ & $7.59 \pm 0.04^{f}$ \\
\hline & & $\mathrm{T} 2$ & $32.79 \pm 0.41^{\mathrm{i}}$ & $29.95 \pm 0.11^{\mathrm{i}}$ & $73.04 \pm 0.15^{\mathrm{fg}}$ & $7.72 \pm 0.03^{\mathrm{e}}$ \\
\hline & & $\mathrm{T} 3$ & $47.56 \pm 0.42^{c}$ & $32.24 \pm 0.29^{g}$ & $86.13 \pm 0.12^{c}$ & $8.18 \pm 0.05^{c}$ \\
\hline & & $\mathrm{T} 4$ & $39.88 \pm 0.40^{\mathrm{f}}$ & $31.38 \pm 0.14^{h}$ & $75.77 \pm 6.80$ ef & $7.91 \pm 0.04^{\mathrm{d}}$ \\
\hline & \multirow{4}{*}{ PG3 } & $\mathrm{T} 1$ & $37.69 \pm 0.45^{g}$ & $31.34 \pm 0.14^{h}$ & $72.40 \pm 0.08^{g}$ & $7.77 \pm 0.07^{\mathrm{e}}$ \\
\hline & & $\mathrm{T} 2$ & $41.37 \pm 0.22^{\mathrm{e}}$ & $33.79 \pm 0.07^{\mathrm{f}}$ & $77.68 \pm 0.19^{\mathrm{e}}$ & $7.96 \pm 0.07^{\mathrm{d}}$ \\
\hline & & T3 & $51.55 \pm 0.50^{b}$ & $37.56 \pm 0.28^{c}$ & $91.13 \pm 0.14^{b}$ & $8.26 \pm 0.03^{b}$ \\
\hline & & $\mathrm{T} 4$ & $46.99 \pm 0.11^{\mathrm{cd}}$ & $35.21 \pm 0.06^{\mathrm{e}}$ & $84.09 \pm 0.08^{c d}$ & $8.12 \pm 0.04^{c}$ \\
\hline & \multirow{4}{*}{ PG4 } & $\mathrm{T} 1$ & $40.13 \pm 0.33^{f}$ & $33.71 \pm 0.05^{\mathrm{f}}$ & $81.09 \pm 0.10^{\mathrm{d}}$ & $7.92 \pm 0.03^{d}$ \\
\hline & & $\mathrm{T} 2$ & $46.69 \pm 0.47^{\mathrm{d}}$ & $36.49 \pm 0.06^{\mathrm{d}}$ & $85.36 \pm 0.34^{c}$ & $8.16 \pm 0.05^{c}$ \\
\hline & & T3 & $59.38 \pm 0.15^{\mathrm{a}}$ & $40.48 \pm 0.04^{\mathrm{a}}$ & $94.24 \pm 0.46^{\mathrm{a}}$ & $8.48 \pm 0.04^{a}$ \\
\hline & & $\mathrm{T} 4$ & $51.33 \pm 0.33^{b}$ & $38.65 \pm 0.42^{b}$ & $90.52 \pm 0.17^{b}$ & $8.28 \pm 0.05^{b}$ \\
\hline \multirow{16}{*}{2020} & \multirow{4}{*}{ PG1 } & $\mathrm{T} 1$ & $24.21 \pm 0.02^{1}$ & $23.74 \pm 0.37^{n}$ & $55.45 \pm 0.38^{h}$ & $7.25 \pm 0.07^{\mathrm{i}}$ \\
\hline & & $\mathrm{T} 2$ & $25.80 \pm 0.13^{k}$ & $24.65 \pm 0.25^{\mathrm{m}}$ & $61.90 \pm 0.09 \mathrm{gh}$ & $7.80 \pm 0.12^{g}$ \\
\hline & & T3 & $36.32 \pm 0.37 \mathrm{~g}$ & $26.82 \pm 0.25^{k}$ & $75.67 \pm 0.26^{\mathrm{de}}$ & $7.90 \pm 0.03^{f}$ \\
\hline & & $\mathrm{T} 4$ & $29.33 \pm 0.60^{j}$ & $25.41 \pm 0.32^{1}$ & $66.55 \pm 0.29 \mathrm{fg}$ & $7.76 \pm 0.08 \mathrm{gh}$ \\
\hline & \multirow{4}{*}{ PG2 } & $\mathrm{T} 1$ & $30.59 \pm 0.45^{i}$ & $27.87 \pm 0.05^{j}$ & $67.99 \pm 0.10^{\text {efg }}$ & $7.70 \pm 0.04^{h}$ \\
\hline & & $\mathrm{T} 2$ & $33.18 \pm 0.19^{h}$ & $30.69 \pm 0.45^{\mathrm{i}}$ & $61.16 \pm 20.67 \mathrm{gh}$ & $7.88 \pm 0.04^{f}$ \\
\hline & & T3 & $48.56 \pm 0.49^{\mathrm{c}}$ & $32.40 \pm 0.33^{g}$ & $86.43 \pm 0.31^{\mathrm{abc}}$ & $8.26 \pm 0.04^{d}$ \\
\hline & & $\mathrm{T} 4$ & $40.84 \pm 0.18^{\mathrm{e}}$ & $31.54 \pm 0.13^{h}$ & $79.13 \pm 1.75^{\mathrm{cd}}$ & $8.05 \pm 0.07^{\mathrm{e}}$ \\
\hline & \multirow{4}{*}{ PG3 } & $\mathrm{T} 1$ & $38.77 \pm 0.38^{f}$ & $31.65 \pm 0.21^{h}$ & $72.70 \pm 0.28$ def & $7.87 \pm 0.07^{\mathrm{f}}$ \\
\hline & & $\mathrm{T} 2$ & $42.24 \pm 0.55^{\mathrm{d}}$ & $34.03 \pm 0.08^{\mathrm{f}}$ & $77.97 \pm 0.07^{\mathrm{cd}}$ & $8.06 \pm 0.06^{\mathrm{e}}$ \\
\hline & & T3 & $52.12 \pm 0.23^{b}$ & $37.76 \pm 0.17^{c}$ & $91.95 \pm 0.08^{\mathrm{ab}}$ & $8.34 \pm 0.04^{c}$ \\
\hline & & $\mathrm{T} 4$ & $47.77 \pm 0.67^{c}$ & $35.62 \pm 0.39^{\mathrm{e}}$ & $84.55 \pm 0.29$ bc & $8.24 \pm 0.05^{\mathrm{d}}$ \\
\hline & \multirow{4}{*}{ PG4 } & $\mathrm{T} 1$ & $40.58 \pm 0.43^{\mathrm{e}}$ & $33.92 \pm 0.07^{\mathrm{f}}$ & $81.36 \pm 0.27^{\mathrm{cd}}$ & $8.06 \pm 0.06^{\mathrm{e}}$ \\
\hline & & $\mathrm{T} 2$ & $47.90 \pm 1.65^{\mathrm{c}}$ & $36.82 \pm 0.23^{d}$ & $85.65 \pm 0.33^{a b c}$ & $8.25 \pm 0.05^{d}$ \\
\hline & & T3 & $60.14 \pm 0.18^{a}$ & $41.39 \pm 0.34^{\mathrm{a}}$ & $94.40 \pm 0.36^{\mathrm{a}}$ & $8.58 \pm 0.02^{\mathrm{a}}$ \\
\hline & & $\mathrm{T} 4$ & $52.00 \pm 0.13^{b}$ & $38.79 \pm 0.44^{b}$ & $90.91 \pm 0.12^{\mathrm{ab}}$ & $8.43 \pm 0.05^{b}$ \\
\hline \multirow{3}{*}{ F-test } & \multicolumn{2}{|c|}{ Phosphogypsum rates (PG) } & $* * *$ & $* * *$ & $* * *$ & $* * *$ \\
\hline & \multicolumn{2}{|c|}{ Inoculation (I) } & $* * *$ & $* * *$ & $* * *$ & $* * *$ \\
\hline & \multicolumn{2}{|c|}{ Interaction $(\mathrm{PG} \times \mathrm{I})$} & $* * *$ & $* * *$ & $* * *$ & $* * *$ \\
\hline
\end{tabular}

Means of the same growing season designated with different letters indicate significant differences among treatments according to the Duncan test $(p<0.05)$. Values are the means \pm standard deviation (SD) from 3 replicates (means \pm SD). PG1-0 tha ${ }^{-1}$; PG2-3 $\mathrm{tha}^{-1} ; \mathrm{PG} 3-6 \mathrm{tha}^{-1}$; PG4-9 $\mathrm{tha}^{-1} ; \mathrm{T} 1-$ A. lipoferum (control); T2-A. lipoferum + B. coagulans; T3-A. lipoferum + B. circulance, and T4-A. lipoferum + B. subtilis; ***-High significant. 

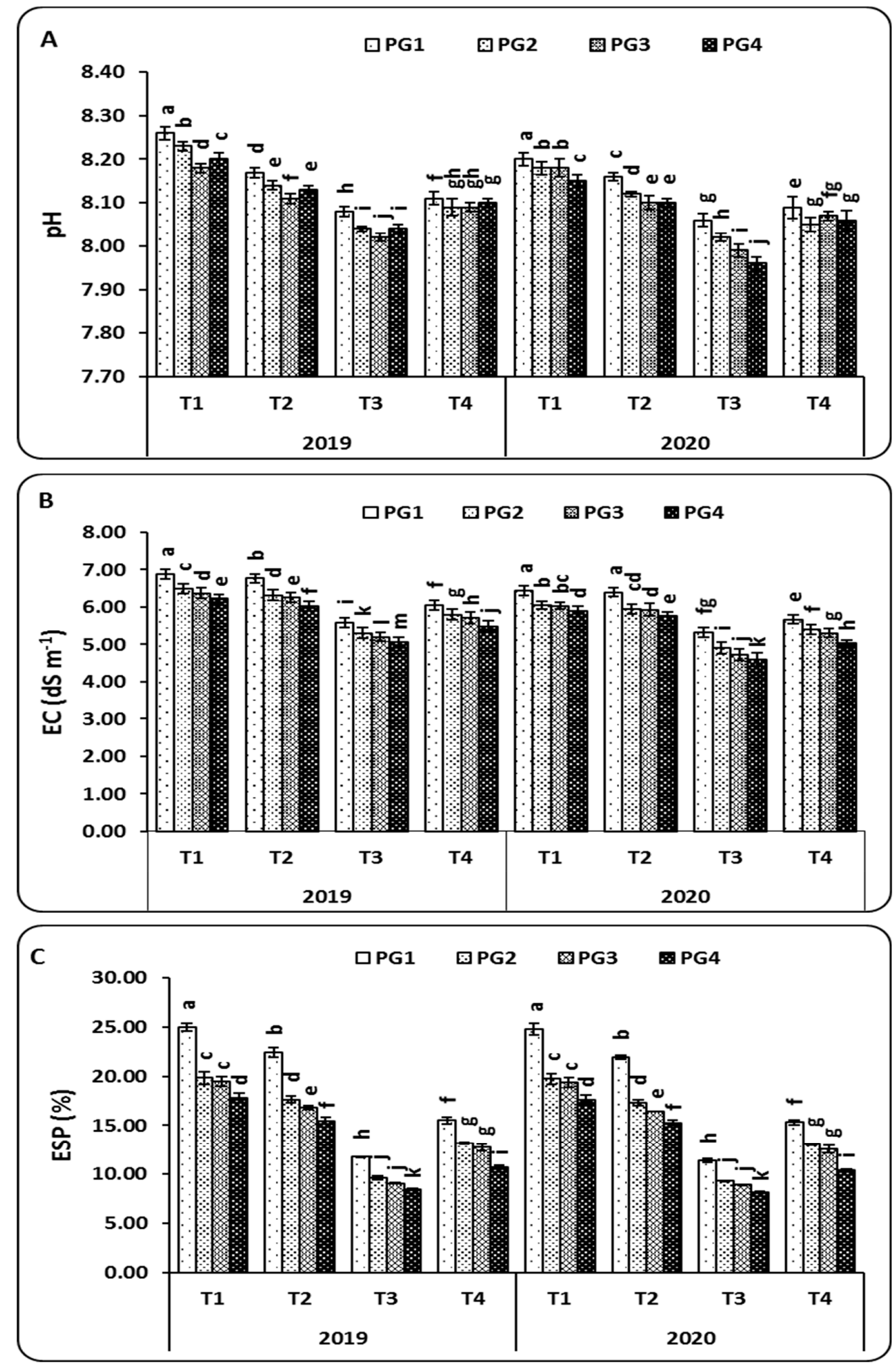

Figure 3. The combined effect of different rates of phosphogypsum and microbial inoculations on soil chemical characteristics pH (A), EC (B), and ESP (C) in salt-affected soils during the 2019 and 2020 seasons. Means of the same growing season designated with different letters indicate significant differences among treatments according to the Duncan test $(p<0.05)$. Values are the means \pm standard deviation (SD) from 3 replicates (means \pm SD). PG1-0 $\mathrm{t} \mathrm{ha}^{-1} ; \mathrm{PG}-3 \mathrm{tha}^{-1} ; \mathrm{PG}-6 \mathrm{tha}^{-1} ; \mathrm{PG} 4-9 \mathrm{tha}^{-1} ; \mathrm{T} 1-$ A. lipoferum (control); T2-A. lipoferum + B. coagulans; T3-A. lipoferum + B. circulance, and T4-A. lipoferum + B. subtilis. 
Table 5. The combined effect of different rates of phosphogypsum and microbial inoculations on yield and yield component of maize plants grown in salt-affected soils during the 2019 and 2020 seasons.

\begin{tabular}{|c|c|c|c|c|c|c|c|}
\hline Year & $\begin{array}{c}\text { Phosphogypsum } \\
\text { Rates (PG) }\end{array}$ & $\begin{array}{l}\text { Inoculation } \\
\text { (I) }\end{array}$ & $\begin{array}{l}\text { Ear Length } \\
(\mathrm{cm})\end{array}$ & $\begin{array}{l}\text { Ear Diameter } \\
\text { (cm) }\end{array}$ & Grains/Ear & $\begin{array}{l}\text { 100-Grain } \\
\text { Weight (g) }\end{array}$ & $\begin{array}{l}\text { Grain Yield } \\
\left(\mathrm{kg} \mathrm{ha}^{-1}\right)\end{array}$ \\
\hline \multirow{16}{*}{2019} & \multirow{4}{*}{ PG1 } & $\mathrm{T} 1$ & $15.97 \pm 0.45^{j}$ & $3.53 \pm 0.12^{j}$ & $387.33 \pm 4.73^{\mathrm{k}}$ & $31.70 \pm 0.10^{1}$ & $4746.66 \pm 45.09^{n}$ \\
\hline & & $\mathrm{T} 2$ & $17.17 \pm 0.21^{\mathrm{i}}$ & $3.70 \pm 0.10 \mathrm{i}$ & $405.00 \pm 3.61^{j}$ & $32.16 \pm 0.21^{k}$ & $5117.66 \pm 14.01^{\mathrm{k}}$ \\
\hline & & T3 & $20.20 \pm 0.26^{d}$ & $3.90 \pm 0.10^{h}$ & $425.00 \pm 3.61^{h}$ & $36.20 \pm 0.70^{c}$ & $5729.66 \pm 28.50^{\mathrm{e}}$ \\
\hline & & $\mathrm{T} 4$ & $19.17 \pm 0.15^{\mathrm{e}}$ & $4.13 \pm 0.06^{\mathrm{fg}}$ & $428.66 \pm 1.53^{g}$ & $33.50 \pm 0.40 \mathrm{fg}$ & $5443.00 \pm 42.14^{h}$ \\
\hline & \multirow{4}{*}{ PG2 } & $\mathrm{T} 1$ & $17.33 \pm 0.42 \mathrm{hi}$ & $4.00 \pm 0.10 \mathrm{gh}$ & $422.00 \pm 3.00^{\mathrm{i}}$ & $32.36 \pm 0.15^{\mathrm{jk}}$ & $5006.33 \pm 16.26^{1}$ \\
\hline & & $\mathrm{T} 2$ & $18.87 \pm 0.15^{\mathrm{e}}$ & $4.16 \pm 0.06^{\mathrm{f}}$ & $429.33 \pm 1.53 \mathrm{~g}$ & $32.70 \pm 0.10^{\mathrm{ij}}$ & $5359.00 \pm 51.12^{i}$ \\
\hline & & T3 & $22.63 \pm 0.15^{b}$ & $4.56 \pm 0.06^{a b c}$ & $449.66 \pm 1.15^{b}$ & $37.66 \pm 0.21^{b}$ & $5936.66 \pm 20.82^{c}$ \\
\hline & & $\mathrm{T} 4$ & $20.03 \pm 0.21^{\mathrm{d}}$ & $4.43 \pm 0.06^{\text {cde }}$ & $437.66 \pm 1.53^{\mathrm{de}}$ & $33.86 \pm 0.15^{f}$ & $5619.66 \pm 17.56^{f}$ \\
\hline & \multirow{4}{*}{ PG3 } & $\mathrm{T} 1$ & $17.67 \pm 0.21$ gh & $4.10 \pm 0.10^{\mathrm{fg}}$ & $426.66 \pm 3.21 \mathrm{gh}$ & $32.60 \pm 0.10^{\mathrm{ij}}$ & $4910.00 \pm 30.00 \mathrm{~m}$ \\
\hline & & $\mathrm{T} 2$ & $17.90 \pm 0.10^{\mathrm{fg}}$ & $4.36 \pm 0.06^{\mathrm{de}}$ & $435.33 \pm 2.08^{e f}$ & $33.13 \pm 0.21 \mathrm{gh}$ & $5431.66 \pm 33.08^{h}$ \\
\hline & & T3 & $22.87 \pm 0.06^{b}$ & $4.63 \pm 0.12^{\mathrm{ab}}$ & $452.00 \pm 1.00^{b}$ & $37.93 \pm 0.25^{b}$ & $6028.66 \pm 23.07^{b}$ \\
\hline & & $\mathrm{T} 4$ & $20.20 \pm 0.26^{d}$ & $4.56 \pm 0.06^{a b c}$ & $439.00 \pm 2.00^{d}$ & $34.53 \pm 0.58^{e}$ & $5752.33 \pm 45.35^{\mathrm{e}}$ \\
\hline & \multirow{4}{*}{ PG4 } & $\mathrm{T} 1$ & $18.23 \pm 0.21^{\mathrm{f}}$ & $4.33 \pm 0.06^{\mathrm{e}}$ & $433.33 \pm 3.51^{\mathrm{f}}$ & $32.96 \pm 0.12 \mathrm{hi}$ & $5236.33 \pm 25.11^{j}$ \\
\hline & & $\mathrm{T} 2$ & $19.17 \pm 0.21^{\mathrm{e}}$ & $4.50 \pm 0.10^{b c d}$ & $436.66 \pm 2.31^{\mathrm{de}}$ & $33.50 \pm 0.26^{\mathrm{fg}}$ & $5534.66 \pm 26.76^{g}$ \\
\hline & & T3 & $24.20 \pm 0.26^{\mathrm{a}}$ & $4.70 \pm 0.10^{\mathrm{a}}$ & $458.00 \pm 1.00^{\mathrm{a}}$ & $38.46 \pm 0.15^{\mathrm{a}}$ & $6235.33 \pm 20.43^{a}$ \\
\hline & & $\mathrm{T} 4$ & $22.10 \pm 0.10^{c}$ & $4.50 \pm 0.10^{b c d}$ & $445.00 \pm 1.00^{c}$ & $35.70 \pm 0.10^{\mathrm{d}}$ & $5846.33 \pm 21.22^{d}$ \\
\hline \multirow{16}{*}{2020} & \multirow{4}{*}{ PG1 } & $\mathrm{T} 1$ & $16.13 \pm 0.40^{j}$ & $3.60 \pm 0.10^{g}$ & $389.00 \pm 3.61^{j}$ & $31.83 \pm 0.21^{h}$ & $4805.67 \pm 45.09^{n}$ \\
\hline & & $\mathrm{T} 2$ & $17.27 \pm 0.21^{\mathrm{i}}$ & $4.03 \pm 0.61^{\mathrm{f}}$ & $414.00 \pm 12.49^{\mathrm{i}}$ & $32.33 \pm 0.06^{\mathrm{gh}}$ & $5186.67 \pm 14.01^{k}$ \\
\hline & & T3 & $20.10 \pm 0.26^{\mathrm{d}}$ & $4.00 \pm 0.10^{\mathrm{f}}$ & $427.00 \pm 4.36^{\mathrm{gh}}$ & $35.00 \pm 2.00^{b c}$ & $5802.00 \pm 31.05^{\mathrm{e}}$ \\
\hline & & $\mathrm{T} 4$ & $19.30 \pm 0.10^{\mathrm{e}}$ & $4.20 \pm 0.10^{\mathrm{def}}$ & $431.00 \pm 1.73^{\mathrm{fg}}$ & $33.57 \pm 0.35^{\text {ef }}$ & $5515.00 \pm 40.73^{h}$ \\
\hline & \multirow{4}{*}{ PG2 } & $\mathrm{T} 1$ & $17.37 \pm 0.38^{\mathrm{i}}$ & $3.97 \pm 0.06^{f}$ & $422.33 \pm 4.51^{\mathrm{h}}$ & $32.37 \pm 0.06^{\mathrm{gh}}$ & $5065.33 \pm 16.26^{1}$ \\
\hline & & $\mathrm{T} 2$ & $18.90 \pm 0.20^{\mathrm{f}}$ & $4.23 \pm 0.06^{\mathrm{c}-\mathrm{f}}$ & $430.67 \pm 2.08 \mathrm{fg}$ & $32.73 \pm 0.06^{\mathrm{fgh}}$ & $5428.00 \pm 51.12^{\mathrm{i}}$ \\
\hline & & T3 & $22.63 \pm 0.12^{b c}$ & $4.53 \pm 0.15^{a b c}$ & $453.33 \pm 2.89^{b}$ & $37.80 \pm 0.20^{\mathrm{a}}$ & $6010.67 \pm 20.82^{c}$ \\
\hline & & $\mathrm{T} 4$ & $20.23 \pm 0.21^{\mathrm{d}}$ & $4.47 \pm 0.06^{\mathrm{a}-\mathrm{d}}$ & $439.67 \pm 2.08^{\mathrm{de}}$ & $33.97 \pm 0.15^{\text {de }}$ & $5690.67 \pm 17.56^{f}$ \\
\hline & \multirow{4}{*}{ PG3 } & $\mathrm{T} 1$ & $17.77 \pm 0.12^{h}$ & $4.10 \pm 0.10^{e f}$ & $427.33 \pm 3.06^{\mathrm{gh}}$ & $32.63 \pm 0.15 \mathrm{gh}$ & $4969.00 \pm 30.00^{\mathrm{m}}$ \\
\hline & & $\mathrm{T} 2$ & $18.00 \pm 0.17 \mathrm{gh}$ & $4.40 \pm 0.10^{b-e}$ & $437.67 \pm 1.15^{\text {de }}$ & $33.23 \pm 0.29$ efg & $5500.67 \pm 33.08^{h}$ \\
\hline & & T3 & $23.00 \pm 0.10^{b}$ & $4.73 \pm 0.12^{\mathrm{a}}$ & $450.67 \pm 5.51^{b}$ & $38.30 \pm 0.20^{\mathrm{a}}$ & $6102.67 \pm 23.07^{b}$ \\
\hline & & $\mathrm{T} 4$ & $20.47 \pm 0.21^{\mathrm{d}}$ & $4.57 \pm 0.06^{\mathrm{ab}}$ & $442.00 \pm 2.00^{\mathrm{cd}}$ & $34.50 \pm 0.44^{\mathrm{cd}}$ & $5823.33 \pm 45.35^{\mathrm{e}}$ \\
\hline & \multirow{4}{*}{ PG4 } & $\mathrm{T} 1$ & $18.30 \pm 0.20^{g}$ & $4.23 \pm 0.15^{\mathrm{c}-\mathrm{f}}$ & $434.33 \pm 3.06^{\mathrm{ef}}$ & $33.10 \pm 0.26^{\text {efg }}$ & $5295.33 \pm 25.11^{j}$ \\
\hline & & $\mathrm{T} 2$ & $19.13 \pm 0.42$ ef & $4.53 \pm 0.06^{a b c}$ & $438.67 \pm 3.21^{\mathrm{de}}$ & $33.63 \pm 0.21$ def & $5603.67 \pm 26.76^{g}$ \\
\hline & & T3 & $24.27 \pm 0.31^{\mathrm{a}}$ & $4.73 \pm 0.06^{\mathrm{a}}$ & $460.00 \pm 1.00^{\mathrm{a}}$ & $38.70 \pm 0.26^{\mathrm{a}}$ & $6309.33 \pm 20.43^{a}$ \\
\hline & & $\mathrm{T} 4$ & $22.50 \pm 0.20^{c}$ & $4.67 \pm 0.06^{\mathrm{ab}}$ & $447.33 \pm 2.08^{b c}$ & $35.87 \pm 0.12^{b}$ & $5917.33 \pm 21.22^{d}$ \\
\hline \multirow{3}{*}{ F-test } & \multicolumn{2}{|c|}{ Phosphogypsum rates (PG) } & $* * *$ & $* * *$ & $* * *$ & $* * *$ & $* * *$ \\
\hline & \multicolumn{2}{|c|}{ Inoculation (I) } & $* * *$ & $* * *$ & $* * *$ & $* * *$ & $* * *$ \\
\hline & \multicolumn{2}{|c|}{ Interaction $(\mathrm{PG} \times \mathrm{I})$} & $* * *$ & $* * *$ & $* * *$ & $* * *$ & $* * *$ \\
\hline
\end{tabular}

Means of the same growing season designated with different letters indicate significant differences among treatments according to the Duncan test $(p<0.05)$. Values are the means \pm standard deviation (SD) from 3 replicates (means \pm SD). PG1-0 tha ${ }^{-1}$; PG2-3 $\mathrm{t} \mathrm{ha}^{-1}$; PG3-6 $\mathrm{tha}^{-1} ; \mathrm{PG} 4-9 \mathrm{t} \mathrm{ha}^{-1} ; \mathrm{T} 1-$ A. lipoferum (control); T2-A. lipoferum + B. coagulans; T3-A. lipoferum + B. circulance, and T4-A. lipoferum + B. subtilis; ${ }^{* *}$-High significant.

In regard to the 100-grain weight, a different increase rate was noticed between the dual microbial inoculation treatments under the PG4 rate $\left(9 \mathrm{tha}^{-1}\right)$ compared to the control (single inoculation), with recorded rates of $1.63 \%$ and $1.60 \%$ with the T2 treatment (A.lipoferum + B. coagulans), $16.68 \%$ and $16.91 \%$ with the T3 treatment (A. lipoferum + B. circulance), and $8.31 \%$ and $8.36 \%$ with the $\mathrm{T} 4$ treatment (A. lipoferum + B. subtilis) during the 2019 and 2020 seasons, respectively (Table 5). On the other hand, a positive effect was caused by the combined application treatment (PG4 + T3) on the grain yields of maize plants, which were 6235.33 and $6309 \mathrm{~kg}^{-1}$ during the 2019 and 2020 seasons, respectively, compared to the other inoculation treatments and different rates of PG (Table 5).

From the results mentioned above, the descending order for the microbial inoculations was T3 > T2 > T4 > T1, while the descending order of the PG rates was PG4 > PG3 > PG2 > PG1. 


\section{Discussion}

In arid and semi-arid regions like Egypt, soil salinity problems have been reported to have a negative impact on soil quality and crop growth [29]. Indeed, saline conditions affect plant growth in two phases. In the first phase, inhibition occurs mainly through the lack of water availability due to the high concentration of the soil solution, and if salt stress continues for a long time, ion toxicity is the main factor that limits the plant metabolism and survival in a second phase [30-32].

The present study aimed to reduce the harmful effect of salt stress on maize plants by single and dual microbial inoculations (A. lipoferum, A.lipoferum $+B$. coagulans, A. lipoferum + B. circulance, and A. lipoferum $+B$. subtilis). Physiological traits, antioxidant enzymes, and physicochemical and biological activities of the soil, as well as nutrient contents and yield, were positively affected when maize plants were exposed to 3,6, and $9 \mathrm{tha}^{-1}$ of PG combined with microbial inoculation in salt-affected soil during the 2019 and 2020 seasons.

\subsection{Physiological Characteristics in Maize Leaves}

It has been proven in previous studies that maize plants are more sensitive to the harmful effect of salinity, which leads to decreases in photosynthetic pigments and physiological properties due to a lack of biosynthesis. Therefore, the improvement in the physiological traits of maize plants grown under salinity stress was lower than those produced with the combined application of PG and microbial inoculation (Table 1). Maize plants exposed to salinity stress (with amendments of PG and microbial inoculation) resulted in increases in chlorophyll and carotenoids and a decrease in proline content, which is attributed to an increase in soil water availability. When using the synergistic effect of PG and microbial inoculation, it increased the available soil water, reduced osmotic stress, and avoided turgor loss under water stress in salt-affected soils compared to control plants (neither PG nor microbial inoculation) $[29,33,34]$. In addition, maize plants inoculated with A. lipoferum + B. circulation with PG4 $\left(9 \mathrm{tha}^{-1}\right)$ led to an amplification of root hydraulic conductivity, which was positively reflected in the chlorophyll pigments compared to untreated plants when exposed to salinity stress $[17,35]$.

\subsection{Antioxidant Enzyme Activities}

Plants have many antioxidant strategies to reduce toxic compounds. Thus, enhancing the antioxidant defense in plants can lead to increased tolerance to various stress factors. Additionally, electrolyte leakage is a key indicator of cell membrane permeability of plants under abiotic stresses, such as salinity, which firstly target the cell membrane [36]. Therefore, the highest activity of antioxidant enzymes alleviates the adverse effect of salinity, especially on cell membrane permeability, through lowering the lipid peroxidation. In addition, to prevent oxidative damage under soil salinity stress conditions, antioxidant enzymatic activities in plants are essential for dealing with the harmful effects of reactive oxygen species (ROS) [29,37,38]. From our results, antioxidant enzymatic activities (CAT, APX, and POD) were significantly increased with increased rates of PG and microbial inoculation (Figure 1). Under $9 \mathrm{t} \mathrm{ha}^{-1}$ of PG, the highest CAT, APX, and POD activities were attained in the maize plants exposed to the T3 treatment (A. lipoferum $+B$. circulation), followed by the plants that were exposed to the T4 treatment (A. lipoferum $+B$. subtilis) and the plants that were exposed to the $\mathrm{T} 2$ treatment (A. lipoferum + B. coagulans) (Figure 1).

These findings are supported by [39], suggesting that wheat plants inoculated with B. phytofirmans strain PsJN could be effectively used to improve the growth and increase the enzyme activities under abiotic stresses. Additionally, [40] suggested that inoculation with A. lipoferum could protect wheat plants from the harmful effects of abiotic stresses through changes in the antioxidant defense system. Smaoui-Jardak [41] reported that PG doses not exceeding 20\% may have caused increasing levels of enzyme activities (CAT, GPX, APX, MDHAR, DHAR, and GR) in tomato plants in saline soil. 


\subsection{Microbial Communities and Soil Enzyme Activities}

In soil, microbial biomass and microbial activity play significant roles in the decomposition of organic matter and the maintenance of soil nutrients [42,43]. From the obtained results (Figure 2 and Table 2), it can be seen that applying PG to saline soil has different effects on the total counts of Azospirillum, Bacillus, and bacteria, as well as on soil enzyme activities (DHA and urease), depending on inoculation treatments and different application rates of PG.

Applying PG $\left(9 \mathrm{t} \mathrm{ha}^{-1}\right)$ with the T3 treatment (A. lipoferum + B. circulation) significantly increased the microbial biomass and soil enzyme activities due to their effects on increasing the levels and availability of soil nutrient contents, as well as increasing soluble organic compounds, which are able to support soil fertility.

These findings are supported by some other researchers; [43] showed that soil amended with $10 \%$ PG significantly improved microbial growth (total counts of bacteria and fungi) and soil enzyme activities (invertase, amylase, and cellulase) compared to different rates of PG. Al-Enazy [15] reported that the highest values of total soil microbial counts were observed in maize plants inoculated with Azotobacter chroococcum, Bacillus megaterium var. phosphaticum, and Pseudomonas fluorescens and treated with $30 \mathrm{~g} \mathrm{PG} \mathrm{kg}^{-1}$. Mahmoud [28] demonstrated that the soil microbial biomass, $\mathrm{CO}_{2}$ evolution, and dehydrogenase activity (DHA) increased significantly in maize plants with the application of PG $\left(10 \mathrm{t} \mathrm{ha}^{-1}\right)$ with nitrogen fertilizer $\left(285 \mathrm{~kg} \mathrm{~N} \mathrm{ha}^{-1}\right)$.

\subsection{The Percentages of Macro-Elements, $\mathrm{Na}^{+}$, and $\mathrm{K}^{+} / \mathrm{Na}^{+}$in Maize Leaves}

The addition of PG with microbial inoculation to saline soil can increase the availability of N, P, and K nutrient cycling in the soil and increase crop production [15]. In the current study (Table 3), the results show that the leaves of inoculated maize plants grown in saline soil had significantly higher macro-nutrient $(\mathrm{N}, \mathrm{P}$, and $\mathrm{K})$ content than uninoculated plants, especially with the synergistic application of PG $\left(9 \mathrm{t} \mathrm{ha}^{-1}\right)$ with microbial inoculation (A. lipoferum + B. circulation). In addition, the $\mathrm{Na}^{+}$content in maize plants was reduced, while the $\mathrm{K}^{+}$content was augmented, resulting in an improved $\mathrm{K}^{+} / \mathrm{Na}^{+}$ratio. In line with our findings, [44] showed that applying soil ameliorants (gypsum and sulfur) with appropriate rhizobial strains is a very important practice to enhance $\mathrm{N}$ uptake in cowpea plants grown in saline soils. Additionally, [15] reported that maize plants grown in saline soils and treated with PG50 $\left(50 \mathrm{~g} \mathrm{~kg}^{-1}\right)$ with co-inoculation (Azotobacter, Bacillus megaterium, and Pseudomonas) increased $\mathrm{N}$ uptake ( $98.32 \mathrm{mg} \mathrm{plant}^{-1}$ ), compared to the control treatment (51.53 mg plant ${ }^{-1}$ ). Similarly, decreasing the content of $\mathrm{Na}^{+}$ions in the leaves of maize plants inoculated with PGPR (Azospirillum lipoferum + Bacillus circulance) under saline soil might be due to the exopolysaccharide produced by PGPR, which binds the $\mathrm{Na}^{+}$ions in the soil, leading to a decrease in its uptake [17].

\subsection{Micro-Elements in Maize Leaves}

There are many microelements $(\mathrm{Fe}, \mathrm{Zn}, \mathrm{Mn}, \mathrm{Cu}$, and $\mathrm{Mo})$ that are essential for plant nutrition, and they are needed in small quantities [45,46]. According to [47], these elements are very important to plants, as they participate in the composition of proteins, DNA, enzymes, amino acids, and photosynthetic processes. In the same context, soil microorganisms can improve plant nutrients by microelements through various methods using appropriate traits that identify them as plant growth promoters $[46,48]$.

The synergistic application of PG $\left(9 \mathrm{tha}^{-1}\right)$ with co-inoculated plants significantly increased the concentrations of microelements compared to single inoculation (Table 4). These results are consistent with the findings of [49], who reported that soil inoculated with mycorrhizal fungi and amended with PG enhanced the element content and growth of wheat plants. In addition, [15] showed that PG along with co-inoculation may be an important approach for ameliorating the negative results of salinity on the plant growth of maize under saline soil conditions. 


\subsection{Soil Physicochemical Characteristics}

The application of PG alone or with microbial inoculation treatments caused a significant decrease in soil pH compared to the control treatment (Figure 3). This decrease can be attributed to the acidifying effect of residual sulfuric acid in PG [26,49]. These results are in agreement with those of $[43,50]$, showing that soil $\mathrm{pH}$ tends to decrease with increasing rates of application of a PG amendment. Although the addition of PG did not have a significant effect on the soil EC and ESP, it is interesting to note that the co-inoculation of bacteria along with $0,3,6$, and $9 \mathrm{tha}^{-1}$ resulted in significant decreases in the EC and ESP values compared to the control (Figure 3). This decrease in soil EC could be explained by the production of exogenous polysaccharides (EPS) by plant growth-promoting rhizobacteria (PGPR), which are able to bind cations, including $\mathrm{Na}^{+}$, and thus, alleviate salt stress in plants grown under saline conditions. Similar to our finding, [51] reported that the co-inoculation of PGPR, including Pseudomonas moraviensis and B. cereus, significantly reduced soil EC. Al-Enazy [14] found that the co-inoculation of maize plants with PGPR, including A. chroococcum, B. megaterium var. phosphaticum, and P. fluorescens, and treated with $50 \mathrm{~g} \mathrm{PG} \mathrm{kg}^{-1}$ significantly reduced soil EC. Additionally, [28] showed that the $\mathrm{pH}$ and EC decreased significantly $(p<0.05)$ with increased PG application rates. For example, PG at a rate of 10 ton ha ${ }^{-1}$ in clay soil with maize plants showed a higher reduction in EC, ranging from $26 \%$ with the recommended nitrogen fertilizer (NF) with the water treatment residual at $5 \mathrm{tha}^{-1}$ (WTR5) to $48 \%$ for NF+PG10 compared with the other treatments.

\subsection{Maize Productivity}

The grain yield and yield-related parameters of maize plants grown in saline soils treated with $9 \mathrm{t} \mathrm{ha}^{-1}$ and inoculated with A. lipoferum + B. circulation increased as compared to the other studied treatments (Table 5). The addition of PG to the soil had positive effects on the maize yield because of its high content of $\mathrm{P}, \mathrm{Ca}$, and $\mathrm{S}$, as well as the improvement of the physicochemical properties of the soil.

These findings are supported by previous studies; [27] demonstrated a positive effect of PG amendment on the biological and chemical properties of soil and cabbage yield in China. Michalovic [52] showed increased productivity of maize plants with PG additions. Smaoui-Jardak [41] suggested that PG application (20\%) seems to be beneficial for increasing the productivity of tomato plants under saline soil conditions. Mahmoud et al. [28] reported that the use of $10 \mathrm{tha}^{-1}$ of PG was optimal for achieving high productivity of maize plants grown in clay soils.

\section{Materials and Methods}

\subsection{Phosphogypsum (PG)}

From a fertilizer industry factory in El-Sharkia Governorate, Egypt, phosphogypsum (PG) was brought to the laboratory and ground, and then passed through a 2-mm screen. The initial physical and chemical properties of PG are as follows: the contents of $\mathrm{Ca}^{2+}$ $\left(\mathrm{meq} \mathrm{L}^{-1}\right), \mathrm{Mg}^{2+}\left(\mathrm{meq} \mathrm{L}^{-1}\right), \mathrm{O} . \mathrm{M}(\%)$, and CEC $\left(\mathrm{cmol} \mathrm{Kg}^{-1}\right)$ were $28.55,3.65,5.68$, and 59.87, respectively. The $\mathrm{pH}$ and EC were 3.65 , and $3.95 \mathrm{dS} \mathrm{m}^{-1}$, respectively. The $\mathrm{pH}$ was measured with a digital $\mathrm{pH}$ meter, and the $\mathrm{EC}$ was measured by a conductivity meter in a 1:5 soil/water ratio [53]. The total contents of $\mathrm{S}, \mathrm{P}, \mathrm{K}, \mathrm{Al}$, and $\mathrm{Cd}$ in the PG were $14.3 \%, 2.32 \%, 0.09 \%, 0.13 \%$, and $2.12 \%$, respectively, which were measured by coupled plasma-optical emission spectrometry (ICP-OES) (PerkinElmer Optima 4300 DV).

\subsection{Microorganisms and Culture Conditions}

One strain of Azospirillum lipoferum SP2 and three strains of Bacillus (B. coagulans NCAIM B.01123, B. circulance NCAIM B.02324, and B. subtilis MF497446) were obtained from Bacteriology Laboratory, Sakha Agricultural Research Station, Kafr El-Sheikh, Egypt. The standard culture conditions were prepared with semi-solid malate medium for A. lipoferum [54], and with nutrient broth medium for the Bacillus strains [55]. 


\subsection{Experimental Setup and Treatments}

In a split-plot design with three replicates, a field experiment was performed in saltaffected soil during the two summer growing seasons at the Sakha Agricultural Research Station, Kafr El-Sheikh Governorate, Egypt, to investigate the application of PG combined with microbial inoculation on chemical and biological soil properties, plant physiology, antioxidant enzymes, macro- and micronutrient contents, and the yield of a moderately salt-sensitive genotype of maize plants (Zea mays L., cv. HSC 10). The main plots were divided into four groups of different PG rates $\left(0,3,6\right.$, and $\left.9 \mathrm{tha}^{-1}\right)$, and the sub-plots $\left(42 \mathrm{~m}^{2}\right.$, 10 rows, $7 \mathrm{~m}$ long, and $0.70 \mathrm{~m}$ apart) were divided by the microbial inoculation treatments (A. lipoferum (control), A. lipoferum + B. coagulans, A. lipoferum $+B$. circulance, and A. lipoferum $+B$. subtilis). The physicochemical and biological properties of the experimental area are presented in Table 6, and the meteorological data are tabulated in Table 7. During the seedbed preparation, phosphorus fertilizer was applied at a rate of $480 \mathrm{~kg} \mathrm{ha}^{-1}$ as calcium superphosphate $\left(15.5 \% \mathrm{P}_{2} \mathrm{O}_{5}\right)$ and $120 \mathrm{~kg} \mathrm{ha}^{-1}$ as potassium sulfate $(48 \%$ $\mathrm{K}_{2} \mathrm{O}$ ), in one dose, while the different rates of PG were incorporated into the soil surface $(0-20 \mathrm{~cm})$ as the final step of seedbed preparation. Nitrogen fertilizer was applied at a rate of $290 \mathrm{Kg} \mathrm{ha}^{-1}$ as urea $(46.5 \% \mathrm{~N}$ ), in equal two doses (at 20 and 40 days of sowing). The seeds of maize were provided by the Maize Research Department, Sakha, Kafr El-Sheikh, Egypt. The seeds were planted on May 7th and 5th in the summer seasons of 2019 and 2020 , respectively, at a rate of $33 \mathrm{~kg} \mathrm{ha}^{-1}$, and then thinned to one plant per hill before the first irrigation. The inoculation treatments were prepared as peat-based inoculums, with $30 \mathrm{~mL}$ of $10^{9} \mathrm{CFU} \mathrm{mL} \mathrm{mL}^{-1}$ from each culture per $60 \mathrm{~g}$ of sterilized carrier, and mixed carefully with the maize seeds before sowing. The plants were irrigated every 12 days and all recommended agricultural practices were followed through the growing seasons according to the Ministry of Agriculture, Egypt.

Table 6. The physical, chemical, and biological characteristics of the experimental area during the two growing seasons of 2019 and 2020.

\begin{tabular}{|c|c|c|c|c|}
\hline \multirow{2}{*}{ Season } & \multicolumn{4}{|c|}{ Character } \\
\hline & pH (1:2.5) & $\mathrm{EC}\left(\mathrm{dS} \mathrm{m}^{-}\right)$ & O.M (\%) & ESP (\%) \\
\hline 2019 & $8.22 \pm 0.02$ & $7.33 \pm 0.04$ & $1.56 \pm 0.01$ & $21.27 \pm 0.17$ \\
\hline 2020 & $8.18 \pm 0.04$ & $7.41 \pm 0.03$ & $1.65 \pm 0.04$ & $20.72 \pm 0.32$ \\
\hline \multirow{2}{*}{ Season } & \multicolumn{4}{|c|}{ Particle Size Distribution (\%) } \\
\hline & Sand & Silt & Clay & Texture grade \\
\hline 2019 & $28.22 \pm 1.66$ & $24.11 \pm 1.83$ & $47.67 \pm 2.01$ & Clayey \\
\hline 2020 & $28.76 \pm 1.78$ & $24.60 \pm 1.92$ & $46.64 \pm 2.11$ & Clayey \\
\hline \multirow{2}{*}{ Season } & \multicolumn{4}{|c|}{ Soluble Cations (meq $\mathrm{L}^{-1}$ ) } \\
\hline & $\mathrm{Ca}^{2+}$ & $\mathrm{Mg}^{2+}$ & $\mathrm{Na}^{+}$ & $\mathrm{K}^{+}$ \\
\hline 2019 & $7.32 \pm 0.66$ & $5.12 \pm 1.22$ & $24.22 \pm 2.09$ & $0.38 \pm 0.09$ \\
\hline 2020 & $8.11 \pm 0.51$ & $5.38 \pm 1.38$ & $23.67 \pm 2.29$ & $0.34 \pm 0.05$ \\
\hline \multirow{2}{*}{ Season } & \multicolumn{4}{|c|}{ Soluble Anions $\left(\right.$ meq L $^{-1}$ ) } \\
\hline & $\mathrm{CO}_{3}{ }^{2-}$ & $\mathrm{HCO}_{3}^{-}$ & $\mathrm{Cl}^{-}$ & $\mathrm{SO}_{4}^{2-}$ \\
\hline 2019 & - & $4.01 \pm 0.55$ & $20.00 \pm 1.29$ & $13.03 \pm 2.11$ \\
\hline 2020 & - & $3.98 \pm 0.37$ & $21.13 \pm 1.86$ & $12.39 \pm 2.02$ \\
\hline \multirow{2}{*}{ Season } & \multicolumn{4}{|c|}{ Available Macronutrients (mg kg ${ }^{-1}$ ) } \\
\hline & $\mathbf{N}$ & & & $\mathbf{K}$ \\
\hline 2019 & $8.81 \pm 0.71$ & & & $322 \pm 17.23$ \\
\hline 2020 & $9.29 \pm 0.45$ & & & $341 \pm 14.11$ \\
\hline
\end{tabular}


Table 6. Cont.

\begin{tabular}{|c|c|c|}
\hline \multirow{2}{*}{ Season } & \multicolumn{2}{|c|}{ Total Counts of Microbes (CFU $\times 10^{5} \mathrm{~g}^{-1}$ dry soil) } \\
\hline & Bacillus * & Azospirillum \\
\hline 2019 & $44 \pm 2.12$ & $23 \pm 1.25$ \\
\hline 2020 & $58 \pm 2.65$ & $35 \pm 1.44$ \\
\hline
\end{tabular}

土: Standard deviation; EC: electrical conductivity (measured in soil paste extract); O.M: organic matter (measured by modified Walkly and Black method, [56]); ESP: exchangeable sodium percentage; *_Total counts of Bacillus were done by pasteurization in a water bath at $70{ }^{\circ} \mathrm{C}$ for $10 \mathrm{~min}$ to kill the vegetative cells.

Table 7. Meteorological data for the two summer growing seasons of 2019 and 2020.

\begin{tabular}{|c|c|c|c|c|c|}
\hline Season & \multicolumn{5}{|c|}{2019} \\
\hline \multirow{2}{*}{ Month } & \multicolumn{2}{|c|}{ Temperature $\left({ }^{\circ} \mathrm{C}\right)$} & \multirow{2}{*}{$\begin{array}{l}\text { Wind Speed } \\
\left(\mathrm{km} \mathrm{day}^{-1}\right)\end{array}$} & \multirow{2}{*}{ RH (\%) } & \multirow{2}{*}{$\begin{array}{c}\text { Rainfall } \\
\left(\mathrm{mm} \mathrm{month}^{-1}\right)\end{array}$} \\
\hline & $\operatorname{Max}$ & Min & & & \\
\hline May & 33.7 & 16.2 & 122.3 & 70.1 & 0.0 \\
\hline June & 35.4 & 18.4 & 117.5 & 66.3 & 0.0 \\
\hline July & 36.5 & 22.5 & 101.2 & 65.7 & 0.0 \\
\hline August & 36.7 & 19.2 & 94.2 & 63.2 & 0.0 \\
\hline September & 32.3 & 18.2 & 84.7 & 67.8 & 0.0 \\
\hline Season & \multicolumn{5}{|c|}{2020} \\
\hline \multirow{2}{*}{ Month } & \multicolumn{2}{|c|}{ Temperature $\left({ }^{\circ} \mathrm{C}\right)$} & Wind Speed & PH (0) & Rainfall \\
\hline & Max & Min & $\left(\mathrm{km} \mathrm{day}^{-1}\right)$ & КH (\%) & $\left(\mathrm{mm}\right.$ month $\left.^{-1}\right)$ \\
\hline May & 33.1 & 17.2 & 125.3 & 68.5 & 0.0 \\
\hline June & 36.2 & 16.4 & 115.2 & 65.7 & 0.0 \\
\hline July & 35.4 & 22.3 & 105.8 & 64.2 & 0.0 \\
\hline August & 38.6 & 23.1 & 93.2 & 62.0 & 0.0 \\
\hline September & 37.1 & 22.5 & 85.2 & 45.9 & 0.0 \\
\hline
\end{tabular}

Max-maximum, min-minimum, $\mathrm{RH}$-relative humidity.

\subsection{Measurements and Analyses}

\subsubsection{Physiological Characteristics in Maize Leaves}

In the fourth topmost fully expanded leaves, the total chlorophyll, carotenoid, and proline concentrations were determined 60 days after sowing. Briefly, $0.5 \mathrm{~g}$ of fresh leaf was homogenized in $1 \mathrm{~mL}$ of acetone $(100 \%)$ for $48 \mathrm{~h}$ at $4{ }^{\circ} \mathrm{C}$, centrifuged for $10 \mathrm{~min}$ at $5000 \times \mathrm{g}$, and the total chlorophyll and carotenoid were calculated according to [57]. For the proline content, $5 \mathrm{~mL}$ of ethanol $(95 \%)$ and $0.2 \mathrm{~g}$ of fresh leaf were homogenized and centrifuged at $5000 \times g$. The supernatant was collected for estimation. Under boiling water bath conditions $\left(100^{\circ} \mathrm{C}\right)$, a mix of $1 \mathrm{~mL}$ of alcoholic extract, $1 \mathrm{~mL}$ of $\mathrm{dH}_{2} \mathrm{O}, 2 \mathrm{~mL}$ of ninhydrin, and $2 \mathrm{~mL}$ of glacial acetic acid was added to test tubes. After $1 \mathrm{~h}$, the reaction was stopped in cold water and mixed with $4 \mathrm{~mL}$ of toluene, and then estimated at $520 \mathrm{~nm}$ using a UV spectrophotometer (Model 6705). Using a standard curve, the proline concentration was expressed as $\mu \mathrm{mol} \mathrm{g}^{-1} \mathrm{FW}$ of leaves [58].

\subsubsection{Assay of Antioxidant Enzyme Activities}

After two months from the date of sowing, the antioxidant enzymes were determined. The reaction contained $50 \mathrm{mM} \mathrm{Na}^{+}$of phosphate buffer (pH 7.0) $+20 \mu \mathrm{L} / \mathrm{mL}$ enzymatic extract $+1 \mathrm{mM} \mathrm{H}_{2} \mathrm{O}_{2}$. At $240 \mathrm{~nm}$, the catalase (CAT) activity $\left(\mu \mathrm{M} \mathrm{H}_{2} \mathrm{O}_{2} \mathrm{~min}^{-1} \mathrm{~g}^{-1} \mathrm{FW}\right)$ was determined according to the methods of [59]. For ascorbate peroxidase (APX) activity, $2 \mathrm{~mL}$ of extraction buffer $\left(90 \mathrm{mM} \mathrm{Na}_{2} \mathrm{HPO}_{4}\right.$ buffer ( $\mathrm{pH} \mathrm{7.8)}$ ) with $8 \%$ glycerol, $1 \mathrm{mM}$ EDTA, and $5 \mathrm{mM}$ ascorbate was homogenized with $0.1 \mathrm{~g}$ fresh leaf. Polyvinyl pyrrolidone $(0.3 \mathrm{~g} / \mathrm{g}$ tissue) was added, and it was then centrifuged at $10,000 \times \mathrm{g}$ for $10 \mathrm{~min}$ at $4{ }^{\circ} \mathrm{C}$. APX activity $\left(\mu \mathrm{M} \mathrm{H}_{2} \mathrm{O}_{2} \min ^{-1} \mathrm{~g}^{-1} \mathrm{FW}\right)$ was determined at $290 \mathrm{~nm}$ by adding $200 \mu \mathrm{L}$ of enzyme extract with $25 \mathrm{mM}$ of phosphate buffer (pH 7.0), $0.1 \mathrm{mM}$ of EDTA, $0.25 \mathrm{mM}$ of ascorbic acid, and $1.0 \mathrm{mM}$ of $\mathrm{H}_{2} \mathrm{O}_{2}$ [60]. At $420 \mathrm{~nm}$, peroxidase (POX) activity (Unit $\min ^{-1} \mathrm{~g}^{-1} \mathrm{FW}$ ) was 
determined by the technique of [61]. The reaction contained $50 \mathrm{mM}$ of phosphate buffer (pH 7.0), $28 \mu \mathrm{L}$ of guaiacol, $100 \mu \mathrm{L}$ of enzymatic extract, and $19 \mu \mathrm{L}$ of $\mathrm{H}_{2} \mathrm{O}_{2}$.

\subsubsection{Microbial Community Estimations}

In the rhizosphere of soil samples, $10 \mathrm{~g}$ was transferred into a glass bottle containing $90 \mathrm{~mL}$ of sterile distilled water and shaken for $0.5 \mathrm{~h}$ at $150 \mathrm{rpm}$. According to [54], the most probable number method was used for the total count of Azospirillum by semi-solid malate medium and calculated using the methods of [62]. The total count of Bacillus was estimated by nutrient agar medium [55] after pasteurizing the soil dilutions $\left(10^{-1}-10^{-3}\right)$. According to the methods of [63], the total count of bacteria was estimated using soil extract agar media. All microbial populations were expressed as the CFU $(\log 10) \mathrm{g}^{-1}$ dry soil at 60 days after sowing.

\subsubsection{Soil Enzyme Activities}

Dehydrogenase (DAH) activity in the soil samples was estimated according to [64]. Briefly, in test tubes, $10 \mathrm{~g}$ of soil sample was mixed with $0.2 \mathrm{~g} \mathrm{CaCO}_{3}$. Then, $1 \mathrm{~mL}$ of 2,3,5-triphenyl tetrazolium chloride (TTC, $3 \%$ ), $1 \mathrm{~mL}$ of glucose solution (1\%), and $8 \mathrm{~mL}$ of $\mathrm{dH}_{2} \mathrm{O}$ were added and then incubated at $30^{\circ} \mathrm{C}$ for $24 \mathrm{~h}$ after the mixture was stoppered with a rubber cork. After incubation, the contents of the test tubes were rinsed down into a small beaker and a slurry was made by adding $10 \mathrm{~mL}$ of methanol. It was then filtered by using Whatman No. 50 filter paper. At $485 \mathrm{~nm}$, the intensity of the red color was measured against a methanol blank using a UV/visible spectrophotometer (Model 6705). By using a standard curve of formazan, the results are expressed as the $\mathrm{mg} \mathrm{TPF}^{-1}$ soil day $^{-1}$.

As adopted from [65], the urease activity of the soil sample was determined. Briefly, in $100 \mathrm{~mL}$-capacity Erlenmeyer flasks, $5 \mathrm{~g}$ of the soil sample was mixed with $0.5 \mathrm{~mL}$ of toluene for $15 \mathrm{~min}$. Then, $10 \mathrm{~mL}$ of phosphate buffer (pH 7.6) and $10 \mathrm{~mL}$ of $10 \%$ urea solution were added and then shaken for $5 \mathrm{~min}$ and incubated at $30^{\circ} \mathrm{C}$ for $24 \mathrm{~h}$. The contents of the flasks were filtered through Whatman No. 42 filter paper after incubation, and the remaining soil sample in the flask had $15 \mathrm{~mL}$ of $\mathrm{KCl}$ solution added $(1 \mathrm{~N})$, and it was shaken for $5 \mathrm{~min}$ before being filtered again; the total filtrate was made up to $100 \mathrm{~mL}$. In a $50 \mathrm{~mL}$ volumetric flask, $1 \mathrm{~mL}$ filtrate was mixed with $1 \mathrm{~mL}$ of sodium and potassium tartrate $(10 \%)$. Then, $1 \mathrm{~mL}$ of gum acacia solution (1\%) and $5 \mathrm{~mL}$ of Nesslers reagent were added, supplementing the volume to $50 \mathrm{~mL}$ with distilled water [66]. Using a UV/visible spectrophotometer (Model 6705), the yellow color was measured at $410 \mathrm{~nm}$. Using a standard curve of $\left(\mathrm{NH}_{4}\right)_{2} \mathrm{SO}_{4}$ solution, the results were expressed as the $\mathrm{mg} \mathrm{NH}_{4}^{+}-\mathrm{N} \mathrm{g}^{-1}$ soil day ${ }^{-1}$.

\subsubsection{Determinations of Macro and Micro-Nutrients in Maize Leaves}

At 60 days after sowing, $0.5 \mathrm{~g}$ of ground leaf sample (the fourth topmost fully expanded leaves) were digested on a hot plate using concentrated sulfuric acid and $30 \% \mathrm{H}_{2} \mathrm{O}_{2}$ according to the methods of [67]. The nitrogen content $\left(\mathrm{mg} \mathrm{plant}^{-1}\right)$ was determined by micro-Kjeldahl, as described by [68]. The phosphorus content $\left(\mathrm{mg} \mathrm{plant}^{-1}\right)$ was estimated spectrophotometrically by the methods of [69]. The $\mathrm{Na}^{+}, \mathrm{K}^{+}$, and the $\mathrm{K}^{+} / \mathrm{Na}^{+}$ratio were determined by a Flame photometer according to the methods of [70]. In addition, the micronutrient contents $\left(\mathrm{mg} \mathrm{plant}^{-1}\right)$ of $\mathrm{Zn}, \mathrm{Mn}, \mathrm{Fe}$, and $\mathrm{Cu}$ were measured using an atomic adsorption spectrophotometer (Perkin Elmer 3300) according to the methods of [70].

\subsubsection{Soil Chemical Characteristics}

Using an augur at 120 days from sowing (harvest), soil samples ( $30 \mathrm{~cm}$ depth) were collected and homogenized as a single sample per replicate. The soil samples were dried in open air, ground, and passed through a $2-\mathrm{mm}$ sieve. The $\mathrm{pH}$ was estimated in a 1:2.5 suspension (soil/distilled water) by a $\mathrm{pH}$ meter (Genway, UK). In the soil paste extract, the EC $\left(\mathrm{dS} \mathrm{m}^{-1}\right)$ was determined using an EC meter (Genway, UK). Based on the equation by [71], the exchangeable sodium percentage (ESP) was measured. 


\subsubsection{Maize Productivity}

After four months from sowing and at a $15.5 \%$ moisture content, the harvest was performed and 10 plants were randomly collected from the fourth inner ridges to estimate yield traits such as the ear length $(\mathrm{cm})$, ear diameter $(\mathrm{cm})$, number of grains per ear, 100-grain weight, and the grain yield $\left(\mathrm{kg} \mathrm{ha}^{-1}\right)$.

\subsection{Statistical Analysis}

Using a split-plot analysis of variances (ANOVA) and SPSS 20.0 software, the data were analyzed. Duncan's multiple range test was used for comparison among the treatment means [72].

\section{Conclusions}

The results of the present study show that maize plant growth and nutrient uptake can be increased by using PG along with bacterial co-inoculation under saline soil conditions. This technique (the combination of PG and microbial inoculation) is considered to be a promising technique for mitigating the harmful effects of soil salinity on plant growth, and this is reflected in an increase in yield. Therefore, the results suggest that applying a PG $\left(9 \mathrm{t} \mathrm{ha}^{-1}\right.$ ) and co-inoculation (A. lipoferum + B. circulance) treatment can significantly increase the plant physiology, antioxidant enzymes, microbial activity, nutrient uptake, and productivity of maize plants under saline soil conditions.

Author Contributions: Conceptualization, A.E.-D.O., M.E., and T.K.; methodology, A.E.-D.O. and T.K.; software, A.E.-D.O.; validation, A.E.-D.O. and T.K.; formal analysis, A.E.-D.O. and T.K.; investigation, A.E.-D.O. and T.K.; resources, A.E.-D.O. and T.K.; data curation, A.E.-D.O., T.K., and M.E.; writing—original draft preparation, A.E.-D.O.; writing—review and editing, A.E.-D.O.; visualization, A.E.-D.O. and T.K.; supervision, A.E.-D.O.; funding acquisition, M.E. All authors have read and agreed to the published version of the manuscript.

Funding: This research received no external funding.

Institutional Review Board Statement: Not applicable.

Informed Consent Statement: Not applicable.

Data Availability Statement: The data that supports the findings of this study are contained within the article or supplementary material and available from the corresponding author upon reasonable request.

Acknowledgments: The authors extend their appreciation to the Deanship of Scientific Research at King Khalid University for funding this work through the Research Groups Project under grant number R.G.P. 1/112/42. All the authors are grateful for the support provided by the Soils, Water and Environment Research Institute (SWERI), Agriculture Research Center (ARC), Egypt.

Conflicts of Interest: The authors declare no conflict of interest.

\section{References}

1. Munns, R. Comparative physiology of salt and water stress. Plant Cell Environ. 2002, 25, 239-250. [CrossRef]

2. Chaudhary, D.; Narula, N.; Sindhu, S.S.; Behl, R.K. Plant growth stimulation of wheat (Triticum aestivum L.) by inoculation of salinity tolerant Azotobacter strains. Physiol. Mol. Biol. Plants 2013, 19, 515-519. [CrossRef]

3. Stamford, N.P.; Figueiredo, M.V.B.; Junior, S.D.S.; Santos, A.; Junior, M.A.L. Effect of gypsum and sulfur with Acidithiobacillus on soil salinity alleviation and on cowpea biomass and nutrient status as affected by PK rock biofertilizer. Sci. Hortic. 2015, 192, 287-292. [CrossRef]

4. Wang, W.; Vinocur, B.; Altman, A. Plant responses to drought, salinity and extreme temperatures: Towards genetic engineering for stress tolerance. Planta 2003, 218, 1-14. [CrossRef]

5. Flowers, T.J.; Galal, H.K.; Bromham, L. Evolution of halophytes: Multiple origins of salt tolerance in land plants. Funct. Plant Biol. 2010, 37, 604-612. [CrossRef]

6. Nabati, J.; Kafi, M.; Nezami, A.; Moghaddam, P.R.; Ali, M.; Mehrjerdi, M.Z. Effect of salinity on biomass production and activities of some key enzymatic antioxidants in Kochia (Kochia scoparia). Pak. J. Bot. 2011, 43, 539-548.

7. Rojas-Tapias, D.; Moreno-Galván, A.; Pardo-Díaz, S.; Obando, M.; Rivera, D.; Bonilla, R. Effect of inoculation with plant growth-promoting bacteria (PGPB) on amelioration of saline stress in maize (Zea mays). Appl. Soil Ecol. 2012, 61, 264-272. [CrossRef] 
8. Kamran, M.; Parveen, A.; Ahmar, S.; Malik, Z.; Hussain, S.; Chattha, M.S.; Saleem, M.H.; Adil, M.; Heidari, P.; Chen, J.-T. An Overview of Hazardous Impacts of Soil Salinity in Crops, Tolerance Mechanisms, and Amelioration through Selenium Supplementation. Int. J. Mol. Sci. 2020, 21, 148. [CrossRef]

9. Munns, R.; Tester, M. Mechanisms of Salinity Tolerance. Ann. Rev. Plant Biol. 2008, 59, 651-681. [CrossRef]

10. Evelin, H.; Kapoor, R.; Giri, B. Arbuscular mycorrhizal fungi in alleviation of salt stress: A review. Ann. Bot. 2009, 104, 1263-1280. [CrossRef]

11. Aghighi Shahverdi, M.; Omidi, H.; Tabatabaei, S.J. Plant growth and steviol glycosides as affected by foliar application of selenium, boron, and iron under $\mathrm{NaCl}$ stress in Stevia rebaudiana Bertoni. Ind. Crop. Prod. 2018, 125, 408-415. [CrossRef]

12. Leal, L.D.S.G.; Pessoa, L.G.M.; de Oliveira, J.P.; Santos, N.A.; Silva, L.F.D.S.; Júnior, G.B.; Freire, M.B.G.D.S.; de Souza, E.S. Do applications of soil conditioner mixtures improve the salt extraction ability of Atriplex nummularia at early growth stage? Int. J. Phytoremediation 2020, 22, 482-489. [CrossRef] [PubMed]

13. Farid, I.; Hashem, A.N.; El-Aty, A.; Esraa, A.M.; Abbas, M.H.; Ali, M. Integrated approaches towards ameliorating a saline sodic soil and increasing the dry weight of barley plants grown thereon. Environ. Biodivers. Soil Secur. 2020, 4, 31-46.

14. El-Gaafarey, T.; El-Nahrawy, S.; El-Nahrawy, S.M. Impact of bio-inoculation with Bradyrhizobium spp. on yield and Seed quality of forage cowpea (Vigna unguiculata L.) under soil salinity conditions. Environ. Biodivers. Soil Secur. 2020, 4, 225-238. [CrossRef]

15. Al-Enazy, A.A.; Al-Barakah, F.; Al-Oud, S.; Usman, A. Effect of phosphogypsum application and bacteria co-inoculation on biochemical properties and nutrient availability to maize plants in a saline soil. Arch. Agron. Soil Sci. 2018, 64, 1394-1406. [CrossRef]

16. Hafez, E.; Omara, A.E.D.; Ahmed, A. The Coupling Effects of Plant Growth Promoting Rhizobacteria and Salicylic Acid on Physiological Modifications, Yield Traits, and Productivity of Wheat under Water Deficient Conditions. Agronomy 2019, 9, 524. [CrossRef]

17. Hafez, E.M.; Osman, H.S.; Gowayed, S.M.; Okasha, S.A.; Omara, A.E.-D.; Sami, R.; Abd El-Monem, A.M.; Abd El-Razek, U.A. Minimizing the Adversely Impacts of Water Deficit and Soil Salinity on Maize Growth and Productivity in Response to the Application of Plant Growth-Promoting Rhizobacteria and Silica Nanoparticles. Agronomy 2021, 11, 676. [CrossRef]

18. Osman, H.S.; Gowayed, S.M.; Elbagory, M.; Omara, A.E.-D.; El-Monem, A.M.A.; Abd El-Razek, U.A.; Hafez, E.M. Interactive Impacts of Beneficial Microbes and Si-Zn Nanocomposite on Growth and Productivity of Soybean Subjected to Water Deficit under Salt-Affected Soil Conditions. Plants 2021, 10, 1396. [CrossRef]

19. Farooq, M.; Wahid, A.; Lee, D.J.; Ito, O.; Siddique, K.H.M. Advances in drought resistance of rice. Crit. Rev. Plant Sci. 2009, 28, 199-217. [CrossRef]

20. Ahemad, M.; Kibret, M. Mchanisms and applications of plantgrowth promoting rhizobacteria: Current perspective. J. King Saud Univ. Sci. 2014, 26, 1-20. [CrossRef]

21. IAEA. Radiation Protection and Management of NORM Residues in the Phosphate Industry; International Atomic Energy Agency: Vienna, Austria, 2013.

22. Saadaoui, E.; Ghazel, N.; Ben Romdhane, C.; Massoudi, N. Phosphogypsum: Potential uses and problems-A review. Int. J. Environ. Stud. 2017, 74, 558-567. [CrossRef]

23. Mazzilli, B.; Palmiro, V.; Saueia, C.; Nisti, M. Radiochemical characterization of Brazilian phosphogypsum. J. Environ. Radioact. 2000, 49, 113-122. [CrossRef]

24. Domingo-Olive, F.; Bosch-Serra, A.D.; Yague, M.R.; Poch, R.M.; Boixadera, J. Long term application of dairy cattle manure and pig slurry to winter cereals improves soil quality. Nutr. Cycl. Agroecosyst. 2016, 104, 39-51. [CrossRef]

25. Mesić, M.; Brezinščak, L.; Zgorelec, Ž.; Perčin, A.; Šestak, I.; Bilandžija, D.; Trdenić, M.; Lisac, H. The application of phosphogypsum in agriculture. Agric. Conspec. Sci. 2016, 81, 7-13.

26. Al-Enazy, A.R.; Al-Oud, S.S.; Al-Barakah, F.N.; Usman, A.R. Role of microbial inoculation and industrial by-product phosphogypsum in growth and nutrient uptake of maize (Zea mays L.) grown in calcareous soil. J. Sci. Food Agric. 2017, 97, 3665-3674. [CrossRef]

27. Lee, C.H.; Ha, B.Y.; Lee, Y.B.; Kim, P.J. Effect of alkalized phosphogypsum on soil chemical and biological properties. Commun. Soil Sci. Plant Anal. 2009, 40, 2072-2086. [CrossRef]

28. Mahmoud, E.; Ghoneim, A.; El Baroudy, A.; Abd El-Kader, N.; Aldhumri, S.A.; Othman, S.; El Khamisy, R. Effects of phosphogypsum and water treatment residual application on key chemical and biological properties of clay soil and maize yield. Soil Use Manag. 2020, 37, 494-503. [CrossRef]

29. Hafez, E.M.; Kheir, A.M.S.; Badawy, S.A.; Rashwan, E.; Farig, M.; Osman, H.S. Differences in physiological and biochemical attributes of wheat in response to single and combined salicylic acid and biochar subjected to limited water irrigation in saline sodic soil. Plants 2020, 9, 1346. [CrossRef]

30. Munns, R. Genes and salt tolerance: Bringing them together. New Phytol. 2005, 167, 645-663. [CrossRef]

31. Sanchez, D.H.; Lippold, F.; Redestig, H.; Hannah, M.A.; Erban, A.; Krämer, U.; Kopka, J.; Udvardi, M.K. Integrative functional genomics of salt acclimatization in the model legume Lotus japonicus. Plant J. 2008, 53, 973-987. [CrossRef]

32. Egamberdieva, D.; Li, L.; Lindström, K.; Räsänen, L.A. A synergistic interaction between salt-tolerant Pseudomonas and Mesorhizobium strains improves growth and symbiotic performance of liquorice (Glycyrrhiza uralensis Fish.) under salt stress. Appl. Microbiol. Biotechnol. 2016, 100, 2829-2841. [CrossRef]

33. Alvarez-Campos, O.; Lang, T.A.; Bhadha, J.H.; McCray, J.M.; Glaz, B.; Daroub, S.H. Biochar and mill ash improve yields of sugarcane on a sand soil in Florida. Agric. Ecosyst. Environ. 2018, 253, 122-130. [CrossRef] 
34. Kheir, A.S.; Abouelsoud, H.M.; Hafez, E.M.; Ali, O.A. Integrated effect of nano-Zn, nano-Si, and drainage using crop straw-filled ditches on saline sodic soil properties and rice productivity. Arab. J. Geosci. 2019, 12, 471. [CrossRef]

35. Abd El-Ghany, T.M.; Masrahi, Y.S.; Mohamed, A.; Abboud, A.; Alawlaqi, M.M.; Elhussieny, A. Maize (Zea Mays L.) Growth and Metabolic Dynamics with Plant Growth- Promoting Rhizobacteria under Salt Stress. J. Plant Pathol. Microbiol. 2015,6 , 305.

36. Bajji, M.; Kinet, J.-M.; Lutts, S. The use of the electrolyte leakage method for assessing cell membrane stability as a water stress tolerance test in durum wheat. Plant Growth Regul. 2002, 36, 61-70. [CrossRef]

37. Osman, H.S.; Salim, B.B.M. Enhancing antioxidants defense system of snap bean under $\mathrm{NaCl}$ salinity using foliar application of salicylic acid, spermidine and glycine betaine. Am. Eurasian J. Agric. Environ. Sci. 2016, 16, 1200-1210.

38. Salim, B.B.; Hikal, M.S.; Osman, H.S. Ameliorating the deleterious effects of saline water on the antioxidants defense system and yield of eggplant using foliar application of zinc sulphate. Ann. Agric. Sci. 2019, 64, 244-251. [CrossRef]

39. Naveed, M.; Mitter, B.; Reichenauer, T.G.; Wieczorek, K.; Sessitsch, A. Increased drought stress resilience of maize through endophytic colonization by Burkholderia phytofirmans PsJN and Enterobacter sp. FD17. Environ. Exp. Bot. 2014, 97, 30-39. [CrossRef]

40. Agami, R.A.; Medani, R.A.; Abd El-Mola, I.A.; Taha, R.S. Exogenous application with plant growth promoting rhizobacteria (PGPR) or proline induces stress tolerance in basil plants (Ocimum basilicum L.) exposed to water stress. Int. J. Environ. Agric. Res. 2016, 2, 78-92.

41. Smaoui-Jardak, M.; Kriaa, W.; Maalej, M.; Zouari, M.; Kamoun, L.; Trabelsi, W.; Abdallah, F.B.; Elloumi, N. Effect of the phosphogypsum amendment of saline and agricultural soils on growth, productivity and antioxidant enzyme activities of tomato (Solanum lycopersicum L.). Ecotoxicology 2017, 26, 1089-1104. [CrossRef] [PubMed]

42. Machulla, G.; Bruns, M.A.; Scow, K.M. Microbial properties of mine spoil materials in the initial stages of soil development. Soil Sci. Soc. Am. J. Soil Sci. 2005, 69, 1069-1077. [CrossRef]

43. Nayak, S.; Mishra, C.S.; Guru, B.C.; Rath, M. Effect of phosphogypsum amendment on soil physico-chemical properties, microbial load and enzyme activities. J. Environ. Biol. 2011, 32, 613-617. [PubMed]

44. Stamford, N.P.; Freitas, A.D.S.; Ferraz, D.S.; Montenegro, A.A.A.; Santos, C.E. Nitrogen fixation and growth of cowpea (Vigna unguiculata) and yam bean (Pachyrhizus erosus) in a sodic soil as affected by gypsum and sulfur inoculated with Thiobacillus and rhizobial inoculation. Trop. Grassl. 2003, 37, 11-19.

45. Kumar, M.; Kour, D.; Yadav, A.N.; Saxena, R.; Rai, P.K.; Jyoti, A.; Tomar, R.S. Biodiversity of methylotrophic microbial communities and their potential role in mitigation of abiotic stresses in plants. Biologia 2019, 74, 287-308. [CrossRef]

46. Shilev, S.; Azaizeh, H.; Vassilev, N.; Georgiev, D.; Babrikova, I. Interactions in Soil-Microbe-Plant System: Adaptation to Stressed Agriculture. In Microbial Interventions in Agriculture and Environment; Singh, D., Gupta, V., Prabha, R., Eds.; Springer: Singapore, 2019.

47. Sandmann, G. Consequences of iron deficiency on photosynthetic and respiratory electron transport in blue-green algae. Photosynth. Res. 1985, 6, 261-271. [CrossRef]

48. Omara, A.; El-Gaafarey, T. Alleviation of Salinity Stress Effects in Forage Cowpea (Vigna unguiculata L.) by Bradyrhizobium sp. Inoculation. Microbiol. Res. J. Int. 2018, 23, 1-16. [CrossRef]

49. Al-Karaki, G.N.; Al-Omoush, M. Wheat response to phosphogypsum and mycrorrhizal fungi in alkaline soil. J. Plant Nutr. 2002, 25, 873-883. [CrossRef]

50. Chung, J.-B.; Kang, S.-C.; Park, S. Short term effect of phosphogypsum on soil chemical properties. Korean J. Environ. Agric. 2001, 20, 317-324.

51. Hassan, T.U.; Bano, A. Role of carrier-based biofertilizer in reclamation of saline soil and wheat growth. Arch. Agron. Soil Sci. 2015, 61, 1719-1731. [CrossRef]

52. Masciarelli, O.; Llanes, A.; Luna, V. A new PGPR co-inoculated with Bradyrhizobium japonicum enhances soybean nodulation. Microbiol. Res. 2014, 169, 609-615. [CrossRef]

53. Richards, L.A. Diagnosis and Improvement of Saline and Alkali Soils; US Salinity Laboratory Staff, US Department of Agriculture: Washington, DC, USA, 1954.

54. Döbereiner, J.; Day, J.M. Associative Symbiosis in Tropical Grasses: Characterization of Microorganisms and Dinitrogen Fixing Sites in Sysposium on Nitrogen Fixation; Washington State University Press: Washington, DC, USA, 1976.

55. Atlas, R.M. Handbook of Microbiological Media, 2nd ed.; CRC Press: New York, NY, USA, 1997; p. 1026.

56. Jackson, M.L. Soil Chemical Analysis; Prentic Hall Pvt. Ltd.: New Delhi, India, 1973.

57. Mousa, N.A.; Siaguru, P.; Wiryowidagdo, S.; Wagih, M.E. Evaluation and selection of elite clonal genotypes of the sweet crop licorice (Glycyrrhiza glabra) in a new environment. Sugar Technol. 2007, 9, 83-94. [CrossRef]

58. Bates, L.S.; Waldren, R.P.; Teare, I.D. Rapid determination of free proline for water-stress studies. Plant Soil 1973, 39, $205-207$. [CrossRef]

59. Aebi, H.E. Catalase. In Methods of Enzymatic Analysis, 3rd ed.; Verlag Chemie: Weinheim, Germany, 1983; pp. $273-286$.

60. Nakano, Y.; Asada, K. Hydrogen peroxide is scavenged by ascorbate-specific peroxidase in spinach chloroplasts. Plant Cell Physiol. 1981, 22, 867-880.

61. Kong, F.X.; Hu, W.; Chao, S.Y.; Sang, W.L.; Wang, L.S. Physiological responses of mexicana to oxidative stress of $\mathrm{SO}_{2}$. Environ. Exp. Bot. 1999, 42, 201-209. [CrossRef]

62. Cochran, D.S. Estimation of bacteria densities by means of the most probable number. Biometrics 1950, 6, 105-116. [CrossRef] [PubMed]

63. Allen, O.N. Experiments in Soil Bacteriology; Wisconsin Univeristy Press: Madison, WI, USA, 1959; p. 202. 
64. Casida, L.E.; Klein, D.A.; Snatoro, T. Soil dehydrogenase activity. Soil Sci. 1964, 98, 371-376. [CrossRef]

65. Pancholy, S.K.; Rice, E.L. Soil enzymes in relation to old succession: Amylase, invertase, cellulose, dehydrogenase and urease. Soil Sci. Soc. Am. Proc. 1973, 37, 47-50. [CrossRef]

66. Campbell, C.R.; Plank, C.O. Preparation of plant tissue for laboratory analysis. In Handbook of Reference Methods for Plant Analysis; Kalra, Y.P., Ed.; CRC Press: Boca Raton, FL, USA, 1998; pp. 37-49.

67. Jones, J.; Wolf, B.J.B.; Mills, H.A. A practical sampling, preparation, analysis, and interpretative guide. In Plant Analysis Handbook; Micro-Macro Publishing: Athens, Greece, 1991.

68. Peters, J.; Combs, S.; Hoskins, B.; Jarman, J.; Kovar, J.; Watson, M.; Wolf, A.; Wolf, N. Recommended Methods of Manure Analysis; University of Wisconsin Cooperative Extension Publishing: Madison, WI, USA, 2003.

69. Page, A.I.; Miller, R.H.; Keeney, D.R. Methods of Soil Analysis: Part 2-Chemical and Microbiological Properties, 2nd ed.; American Society of Agronomy: Madison, WI, USA, 1982.

70. Cottenie, A.; Verloo, M.; Kiekens, L.; Velghe, G.; Camerlynck, R. Chemical Analysis of Plants and Soils; Laboratory of Analytical and Agrochemistry, State University: Ghent, Belgium, 1982; pp. 14-24.

71. Arshad, M.; Lowery, B.; Grossman, B. Physical tests for monitoring soil quality. In Methods for Assessing Soil Quality; Doran, J.W., Jones, A.J., Eds.; Special Publication 49; Soil Science Society of America: Madison, WI, USA, 1997; pp. $123-141$.

72. Duncan, D.B. Multiple Range and Multiple F Tests. Biometrics 1955, 11, 1-42. [CrossRef] 